\title{
The Role of Atlantic Ocean-Atmosphere Coupling in Affecting North Atlantic Oscillation Variability
}

\author{
Arnaud Czaja \\ Massachusetts Institute of Technology, Cambridge, Massachusetts, USA \\ Andrew W. Robertson \\ International Research Institute for Climate Prediction, Palisades, New York, USA \\ Thierry Huck \\ Laboratoire de Physique des Océans, Brest, France
}

\begin{abstract}
We review the role of ocean-atmosphere interactions over the Atlantic sector in North Atlantic Oscillation (NAO) variability. The emphasis is on physical mechanisms, which are illustrated in simple models and analyzed in observations and numerical models. Some directions of research are proposed to better assess the relevance of Atlantic air-sea interactions to observed and simulated NAO variability.
\end{abstract}

\section{INTRODUCTION}

In Thompson et al. [this volume], it was suggested that extratropical atmospheric dynamics alone might set the horizontal and vertical scales of North Atlantic Oscillation (NAO) variability, as well as its background 'white' temporal spectrum. This is a notable feature of extra-tropical climate variability since, unlike the tropical Pacific where both oceanic and atmospheric dynamics are needed to create a strong interannual signal like El Niño-Southern Oscillation (ENSO), NAO variability on timescales of months to decades might primarily reflect intrinsic atmospheric processes alone. The atmospheric cap north of the equator is, however, not an isolated system.It exchanges heat, moisture and momentum with the ocean, the land, the biosphere and the cryosphere below, as well as with the tropics at its southern boundary. All these interactions could possibly influence NAO variability on certain timescales. To motivate this statement, we show (Figure 1) a comparison between the observed boreal winter (DJF) NAO index and that simulated by an ensemble of atmospheric general circulation model (GCM) experiments forced by the observed, global, time-varying sea surface temperature (SST) and sea

The North Atlantic Oscillation:

Climatic Significance and Environmental Impact

Geophysical Monograph 134

Copyright 2003 by the American Geophysical Union 10.1029/134GM07 ice anomalies over 1947-1997. One clearly observes some skill in reproducing the low-frequency time evolution of the NAO index over the last decades. Although the interpretation of these experiments is subtle [Bretherton and Battisti, 2000; Czaja and Marshall, 2000], this quite realistic NAO simulation would be impossible if SST anomalies and/or sea ice anomalies had no impact on the NAO. In this chapter, we will focus on the potential role of the Atlantic Ocean in providing such a modulation of intrinsic NAO variability. We have chosen to decompose NAO Atlantic Ocean interactions into two distinct physical frameworks, according to whether or not they involve ocean dynamics. Each framework is now introduced in turn.

It is firmly established from both observational [e.g., Cayan, 1992; Halliwell and Mayer, 1996; Deser and Timlin, 1997] and modeling studies [e.g., Battisti et al., 1995; Halliwell, 1998] that NAO variability intrinsic to the atmosphere drives large-scale changes in SST over the North Atlantic. Changes in windspeed of the westerlies and the trade winds, associated with the NAO, lead to a modulation of turbulent heat loss at the ocean surface and entrainment at the base of the ocean mixed layer. In addition, changes in surface windstress drive anomalous Ekman currents that add constructively to these forcings north of $30^{\circ} \mathrm{N}$ [e.g., Marshall et al., 2001a; Visbeck et al., this volume]. Thus, even in the absence of further dynamical effects associated with geostrophic ocean circulation (see below), intrinsic NAO variability drives a tripolar anomaly pattern in SST (Figure 2). 


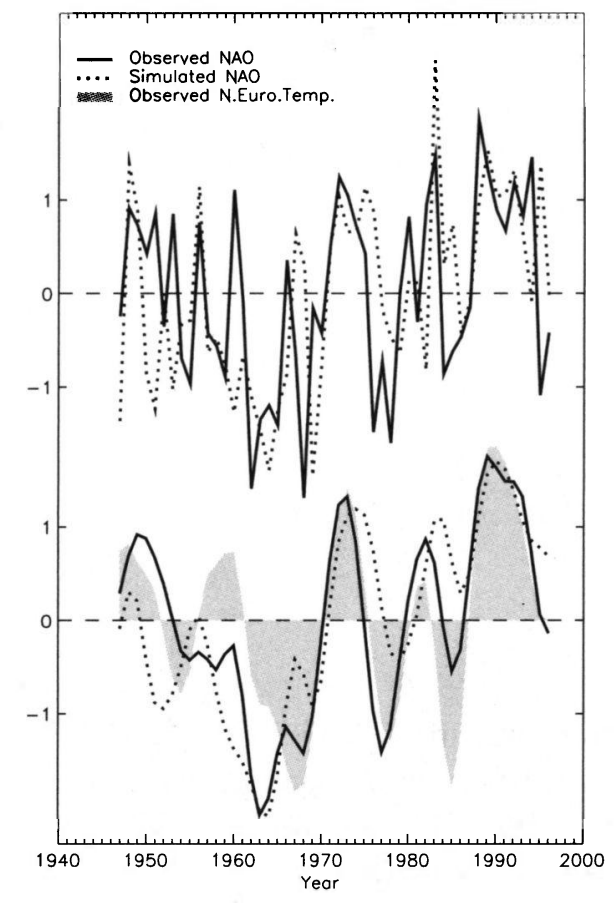

Figure 1. Observed (solid line) and modeled ensemble average (dotted line) of the normalized winter (DJF) NAO index. The lower graph shows the normalized NAO index time series after they have been filtered to pass variations with periods greater than 6.5 years. Shading in lower graph is the normalized filtered time series of observed North European surface temperature (averaged over $5-50^{\circ} \mathrm{E}, 50-70^{\circ} \mathrm{N}$ ). The year corresponds to December for each DJF season. From Rodwell et al. [1999].

A more open question is the extent to which NAO variability is substantially modified by the presence of the SST tripole.

If air-sea interactions were purely local in space, one would expect thermal equilibration between the upper ocean and the troposphere through surface heat flux to become important in setting the amplitude of temperature anomalies in both fluids. Inspection of temperature anomalies in the free troposphere associated with NAO (Figure 2, contours) indeed suggests a certain degree of thermal equilibration, with warm air above warm SST and cold air above cold SST, and a similar amplitude of perturbation $\sim 0.3 \mathrm{~K}$ ). The feedback of the SST tripole onto the NAO is, however, expected to be more complex because of nonlocal dynamical effects. In particular, since the temperature anomalies in Figure 2 extend meridionally from the equator to the North Pole, very different mechanisms are involved. The two northern centers of action of the SST tripole modulate the SST gradient in middle latitudes, which could impact the storm track and subsequently the large-scale atmospheric flow. Changes in SST associated with the southern lobe of the SST tripole modulate the cross-equatorial SST gradient and diabatic heating associated with the Intertropical Convergence Zone (ITCZ) and South American monsoon, which could feedback onto the NAO through forced Rossby wavetrains and/or changes in the sectorial Hadley circulation. Below, the relative roles of local thermal equilibration and nonlocal SST feedbacks will be discussed in the light of a linear stochastic climate model. In addition, we will review the physical mechanisms as well as the observational and modeling support for a feedback of the SST tripole on the NAO.

The fact that the Atlantic Ocean is not just a heat reservoir providing sources and sinks of energy for NAO variability, but also carries energy horizontally, introduces new features to Atlantic air-sea interactions. In particular, it makes $\mathrm{NAO/Atlantic} \mathrm{Ocean} \mathrm{interactions} \mathrm{not} \mathrm{merely} \mathrm{restricted} \mathrm{to}$ $\mathrm{NAO/SST}$ tripole interactions. It is firmly established from observations and numerical simulations that NAO variability drives large-scale anomalies in currents, density and water masses of the North Atlantic Ocean. As reviewed in Visbeck et al. [this volume], the dynamical ocean response can occur on a broad range of timescales with distinct spatial patterns. Various observational studies have shown a fast response of the Gulf Stream/recirculation system to NAO variability (about a 1-year lag), leading to localized SST anomalies north of the Gulf Stream extension [e.g., Taylor and Stephens, 1998; Frankignoul et al., 2001b]. On longer (decadal and interdecadal) timescales, the ocean response involves basin-scale currents and SST anomalies, as hinted at in various numerical studies [e.g., Visbeck et al., 1998; Krahman et al., 2001; Eden and Jung, 2001; Eden and Willebrandt, 2001]. In addition, like the atmosphere, the ocean circulation displays intrinsic variability on a broad range of timescales (e.g., interannual to decadal associated with the wind-driven gyres, interdecadal timescales associated with the meridional overturning circulation (MOC)). The possibility then, that ocean circulation changes forced by the NAO, or intrinsic to the Atlantic Ocean, might influence the NAO through their impact on the SST field allows coupled atmosphere-ocean variability on timescales set by ocean dynamics.

In a series of papers, Bjerknes $[1958 ; 1962 ; 1964]$ was the first to raise this issue, and argued that interdecadal fluctuations of the zonal index [a possible NAO index, see Hurrell et al., this volume] might reflect compensation between changes in oceanic and atmospheric energy transport. In his own words,

"The [above] hypothesis concerning quasi constant total meridional heat flux and opposite fluctuations of its oceanic and atmospheric parts, does explain the possibility of relatively big variations in climate without having recourse to primary solar changes." [Bjerknes, 1964]. 

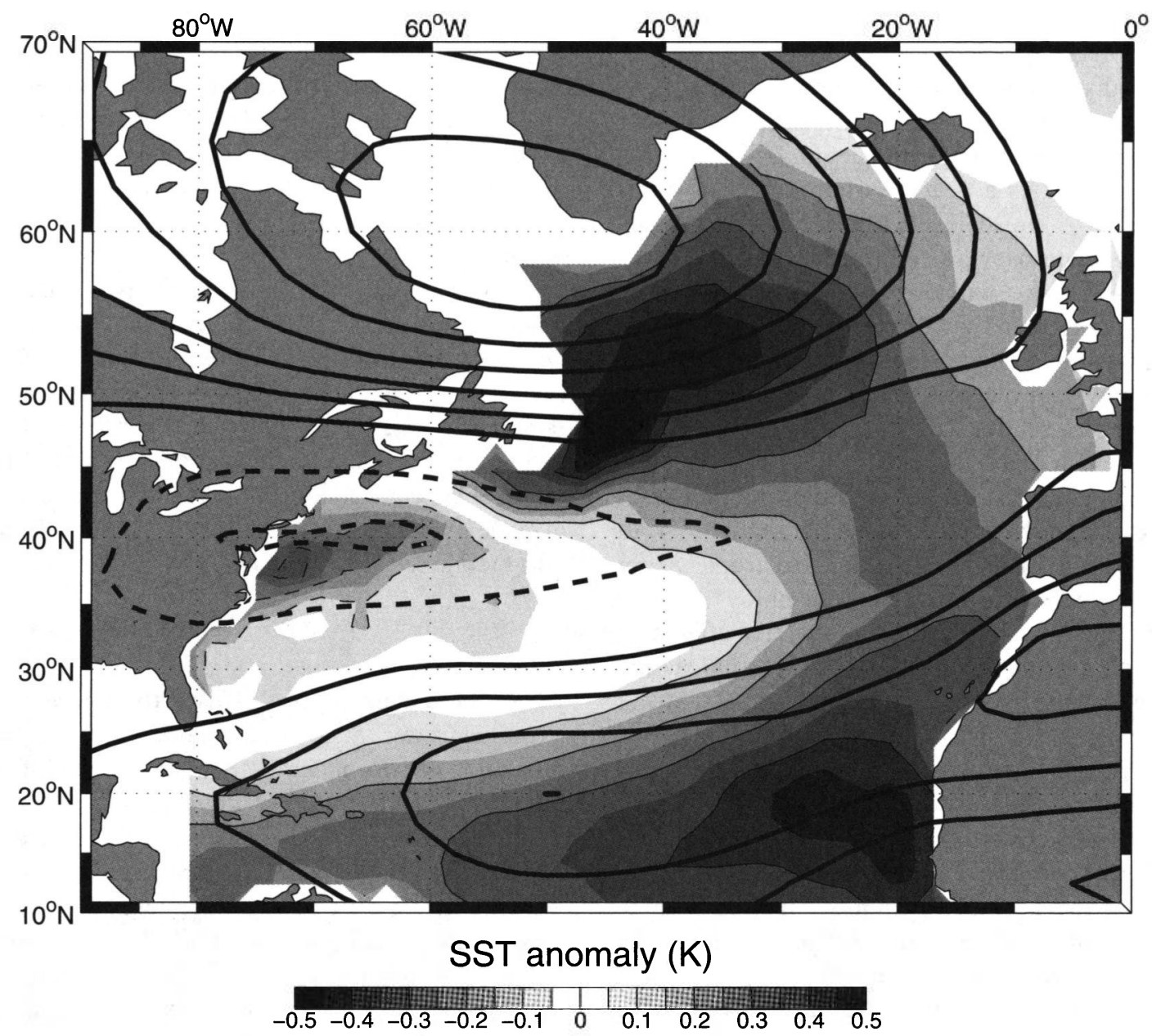

Figure 2. Dominant pattern of covariability between monthly temperature at $500 \mathrm{mb}$ (contoured every $0.1 \mathrm{~K}$, dashed when negative) and SST (shaded with dashed contours when negative). Anomalies from the NCEP/NCAR reanalysis data (1958-1999), as found in a maximum covariance analysis [also called SVD in the literature, see Bretherton et al., 1992]. The mode explains $55 \%$ of the square covariance between the temperature fields. All months were considered in the analysis, not only wintertime.

Since Bjerknes' works the observational record has just gained a few decades. It is still too limited in its oceanic coverage (both horizontally and vertically) and its description of the radiative and diabatic processes in the atmosphere to allow a direct investigation of the fluctuations in atmosphere-ocean energy budget at timescales longer than a few years. Nevertheless, the analysis of more conventional surface climate variables like SST, surface winds, and surface pressure collected over the past century has provided some support for, and has refined, Bjerknes earlier findings. Two dominant climate signals involving the NAO and perhaps the ocean circulation have now been identified in the observational record, at decadal and interdecadal timescales. In this review, the limited description of these signals that can be gained from the observational record will be complemented by a parallel discussion of results obtained from a hierarchy of coupled ocean-atmosphere models. The latter show a wide range of behavior, from middle latitude coupled modes on decadal timescales to intrinsic oceanic variability imprinting weakly on the NAO, while some indicate a purely passive oceanic response to an essentially stochastic NAO. This diversity of results reflects the richness of the problems posed by Atlantic air-sea interactions, but also severely limits our ability to draw firm conclusions concerning the true impact of the Atlantic Ocean on NAO variability.

The chapter is structured as follows. We begin in section 2 with an illustration of the null hypothesis for NAO variability, referred to as the climate noise scenario in the following. It proposes that $\mathrm{NAO}$ variability on interannu- 
al and longer timescales simply reflects the year to year, or decades to decades, changes of its short timescale (weeks to months) statistics, i.e. intrinsic to the atmosphere. This defines a reference for the subsequent scenarios discussed in the chapter. In section 3 , we discuss the role of the ocean as a heat reservoir for NAO variability. We begin by presenting a stochastic energy balance model of the atmosphere and the ocean mixed layer (section 3.1), which we will use to analyze the role of local thermal interactions and nonlocal dynamical SST feedbacks in providing departures from the climate noise scenario. The physical mechanisms of SST feedback are further discussed in section 3.2 for the middle latitudes, and in section 3.3 for a possible remote influence from the tropical Atlantic. Observational evidence of the impact of SST anomalies on the NAO is discussed in section 3.4. In section 4 , we discuss the modifications to troposphere/ ocean mixed layer interactions introduced by Atlantic Ocean currents. Section 4.1 illustrates advective effects on air-sea interactions at the boundary of the subtropical and subpolar gyres of the North Atlantic, while section 4.2 focuses on basin-scale ocean-atmosphere interactions, possibly involving the ocean's meridional overturning circulation. In both, a parallel discussion of observations and coupled models will be given. Section 5 offers a concluding assessment of the relevance of coupled processes to NAO variability, and some suggestions for future research.

This review clearly overlaps with other recent reviews by Latif $[1998$; interdecadal variability simulated by coupled models], by Marshall et al. [2001b; mechanisms and observations of Atlantic climate variability], and by Kushnir et al. [2002; the response of atmospheric GCMs to extratropical SST anomalies]. Several new aspects, however, are worth noting. The climate noise paradigm discussed in section 2 , as well as the dynamics governing remote forcing of extra-tropical climate variability from the tropics (section 3.3), are topics which, to our knowledge, have not been discussed previously in the context of NAO variability. The thermal interaction of the troposphere and the upper ocean (section 3 ) is described in detail and compared to some original and unpublished research on the subject. An effort is made throughout the review to first illustrate basic ideas with simplified models, and then test these ideas against the observations and more complex models. The aim is to bring together theories, statistics, observations and model outputs.

\section{THE CLIMATE NOISE PARADIGM}

Prior to investigating the oceanic influence on NAO variability, it is useful to consider a simpler interpretation, or null hypothesis, for the existence of NAO variability on interannual and longer timescales. We will refer to this interpretation as the climate noise paradigm [Leith, 1973; Madden, 1981]. Briefly, it argues that the observed interannual and longer timescale NAO fluctuations are essentially a remnant of its energetic weekly to monthly fluctuations. In this view, NAO variability is entirely driven by processes intrinsic to the atmosphere.

Let us consider a first-order autoregressive process $(\mathrm{AR}(1))$, with daily variance $\sigma^{2}$ and lag one-day autocorrelation $\gamma$ [Box et al., 1993]. A realization of such a process would show fluctuations on all timescales, with the visual impression of larger fluctuations on timescales close to its persistence time $\tau$ ( $\tau=-1 / 1 \mathrm{n} \gamma$ days for the AR(1) process), and weaker amplitude fluctuations on timescales longer than $\tau$. One can actually show that the variance $\sigma_{C N}^{2}$ of the average time series (over $N$ days) constructed from the daily AR(1) time series is [Madden, 1981]

$\sigma_{C N}^{2}=\frac{\sigma^{2}}{N}\left[1+2(1-1 / N) \gamma+2(1-2 / N) \gamma^{2}+\ldots+2 / N \gamma^{N-1}\right](1)$

where the underscript $C N$ is used to indicate the variance expected from climate noise. The ratio $\sigma^{2}{ }_{C N} / \sigma^{2}$ is plotted as a function of $\gamma$ for monthly ( $N=30$ days), seasonal $(N=90$ days), and yearly ( $N=365$ days) averages in Figure 3. As expected, when the AR(1) process is nearly decorrelated at one day $(y \sim 0)$, the ratio becomes inversely proportional to $N$, with only $3 \%$ of the variance retained by the monthly time series. It can be seen in Figure 3 that the persistence of the process compensates for this decline with, in the limit of large persistence $(\gamma \rightarrow 1)$, a ratio of unity. Interestingly, one observes a sharp transition for $\gamma>0.8$, indicating that a significant fraction of the variance is retained in the averaged

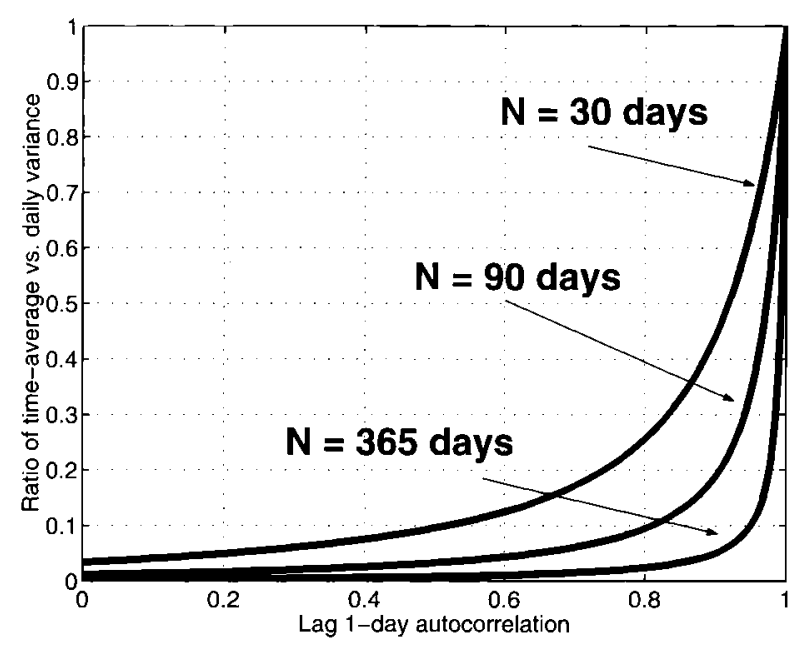

Figure 3. Ratio of time average over daily variance $\sigma_{C N}^{2} / \sigma^{2}$ as a function of the 1-day autocorrelation $\gamma$. Several choices of time average $\mathrm{N}$ are shown, as indicated on the plot. 
time series when the process is sufficiently persistent $(\gamma=$ 0.8 corresponds to a persistence time of 4.5 days).

Feldstein [2000] recently investigated the relevance of the AR(1) model to the observed NAO. Using geopotential height anomalies at $300 \mathrm{mb}$ from the NCEP/NCAR reanalysis, he produced a daily NAO index, deduced from a rotated principal component analysis. Feldstein found a good fit of the observed NAO intraseasonal spectrum to that of an AR(1) with a persistence time of 9.5 days (Figure 4, right curves), clearly governed by atmospheric dynamics [Thompson et al., this volume]. This timescale corresponds to a value $\gamma=0.9$, for which $45 \%$ of the variance is retained in the monthly time series, a number decreasing to $20 \%$ and $5 \%$ for the seasonal and annual time series (Figure 3). Actual comparison of the interannual NAO index spectrum (Figure 4, left thick curve) with the energy level expected from climate noise (lowest thin curve on the left) indicates that the climate noise prediction is about a factor of 2 to 3 too low. The related increase in interannual variance of the observed NAO index compared to $\sigma^{2} \mathrm{CN}$ is about $60 \%$ (from Table 2 of Feldstein [2000], $\chi^{2}$ $/ N-1)$, suggesting significant interactions of the troposphere with other components of the climate system to shape the net NAO variability.

In the following sections, we will show that the finite heat capacity of the upper ocean, SST feedbacks and the Atlantic

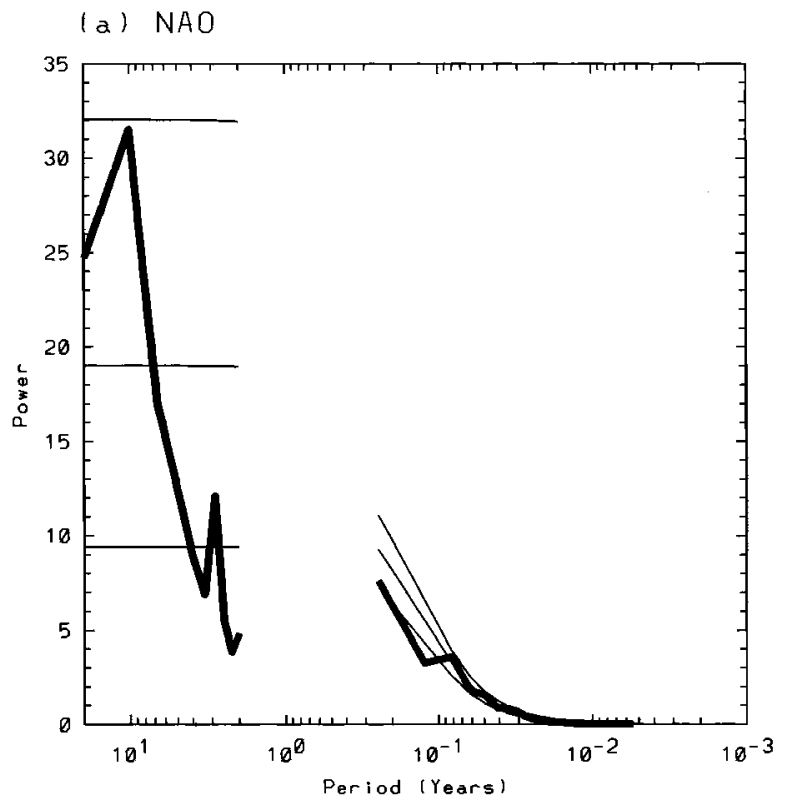

Figure 4. Intraseasonal (right thick curve) and interannual (left thick curve) spectrum of an observed NAO index. The red noise or AR(1) spectrum (lowest thin line), and its a priori (middle thin line) and a posteriori (upper thin line) $95 \%$ confidence levels are also shown. From Feldstein [2000; his Figure 4].
Ocean circulation can be expected to redden and modulate NAO variability in various frequency bands. Nevertheless, it must be kept in mind that the redness of dynamical NAO indices is weak and controversial. Wunsch [1999] found that the spectrum of Hurrell's index [Hurrell, 1995], based on a longer time series than that used by Feldstein [2000], is essentially white [but see also Stephenson et al., 2000], and it can be pointed out that the factor 2 to 3 discrepancy between climate noise and observed spectra is within the estimated error bars (medium and upper thin lines in Figure 4). This suggests that an analysis of the impact of the ocean on NAO variability should not be limited to the sole time series analysis of dynamical NAO indices, like those based on pressure or temperature. Other variables show clearer signatures of an alternative to the climate noise scenario. This will be emphasized in section 5 .

\section{THE NORTH ATLANTIC OCEAN AS A HEAT RESERVOIR}

In this section we take a first step in understanding the impact of the Atlantic Ocean on NAO variability, by studying Atlantic air-sea interactions in the absence of ocean currents. By developing a stochastic model of the atmosphere and the ocean mixed layer, it will be seen that local thermal coupling can redden dynamical NAO spectra but that this effect is substantially modulated by any nonlocal dynamical feedbacks of SST anomalies onto the atmosphere (section 3.1). The latter are discussed further in sections 3.2 and 3.3, and searched for in the observations in section 3.4. Section 3.5 summarizes the main results.

\subsection{The Reduced Thermal Damping Argument}

In a purely one-dimensional (vertical) framework, there should be a local adjustment of atmospheric and oceanic temperature anomalies on a timescale set by the finite heat capacity of the ocean mixed layer (a few months). Barsugli and Battisti [1998] noticed further that on longer timescales the anomalous heat exchange between the atmosphere and the ocean mixed layer would vanish, thereby reducing the damping of oceanic and atmospheric thermal anomalies. This could introduce departures from climate noise for the spectra of SST and atmospheric temperature anomalies, by reddening the latter on monthly to interannual timescales. To illustrate this idea, referred to in the following as the reduced thermal damping argument, and take into account (although still crudely) further complications associated with nonlocal dynamical effects, we analyze below the onedimensional energy balance model developed by Barsugli and Battist $[$ [1998; hereafter BB]. 
The atmosphere is represented as a slab at temperature $T_{a}$ that exchanges energy with a slab ocean mixed layer at temperature $T_{o}$ (the SST). The fluctuations of $T_{a}$ and $T_{o}$ can be thought of as that of the NAO and the SST tripole, respectively. For small deviations with respect to the stationary state (denoted by a prime), the conservation of energy for each component can be written as

$$
\begin{gathered}
\gamma_{a} \frac{d T_{a}^{\prime}}{d t}=-\lambda_{s a}\left(T_{s}^{\prime}-T_{o}^{\prime}\right)-\lambda_{a} T_{a}^{\prime}+F_{a}^{\prime} \\
\gamma_{o} \frac{d T_{o}^{\prime}}{d t}=\lambda_{s o}\left(T_{s}^{\prime}-T_{o}^{\prime}\right)-\lambda_{o} T_{o}^{\prime}
\end{gathered}
$$

where $\gamma_{a, o}$ denote the heat capacity for the column-averaged atmosphere and the ocean mixed layer respectively, and $\lambda_{a, o}$ represent the corresponding radiative damping coefficients (see BB for a derivation). The turbulent heat exchange at the air-sea interface is assumed proportional to the air-sea temperature difference $T_{S}^{\prime}-T_{0}^{\prime}$, with $T_{S}^{\prime}=c T_{a}^{\prime}$ and $c$ a model parameter setting the vertical scale of atmospheric temperature anomalies. All dynamical processes are encapsulated in the anomalous convergence of atmospheric energy transport $F_{a}^{\prime}$. It is simply parameterized as

$$
F_{a}^{\prime}=\lambda_{s a}\left(N+(b-1) T_{o}^{\prime}\right)
$$

where $N$ is a stochastic component representing the forcing of temperature anomalies by transient and stationary eddies associated with the turbulent flow of the atmosphere in middle latitudes. The second term on the r.h.s of (4) represents a sensitivity of atmospheric energy transport convergence to SST, where $b$ is a non-dimensional parameter. The latter controls the net feedback of a SST anomaly onto the atmospheric dynamics, i.e. the sum of 'thermal' $\lambda_{s a} T_{o}^{\prime}$ and 'dynamical' $\lambda_{s a}(b-1) T_{o}$ ' effects in (2). The linear decomposition (4) thus introduces a random component, $N$, assumed to be solely determined by intrinsic atmospheric dynamics, and a slowly evolving part associated with SST forcing. Other decompositions could be envisioned with, for instance, a dependence of $N$ on SST [non-deterministic SST feedback - see an illustration in Neelin and Weng, 1999]. It will be seen below that $b$ is the crucial parameter of the model. Standard values for the parameters are taken from BB, namely: $c=1, b=0.5$, $\lambda_{s a}=23.9 \mathrm{~W} \mathrm{~m}^{-2} \mathrm{~K}^{-1}, \lambda_{s o}=23.4 \mathrm{~W} \mathrm{~m}^{-2} \mathrm{~K}^{-1}, \lambda_{a}=2.8 \mathrm{~W} \mathrm{~m}^{-2}$ $\mathrm{K}^{-1}, \lambda_{o}=1.9 \mathrm{~W} \mathrm{~m} \mathrm{~K}^{-1}, \gamma_{a}=10^{7} \mathrm{~J} \mathrm{~m}^{-2} \mathrm{~K}^{-1}, \gamma_{o}=2.10^{8} \mathrm{~J} \mathrm{~m}^{-2} \mathrm{~K}^{-1}$ (50 m mixed layer depth). Note that both atmospheric and oceanic heat capacities will be increased by a factor 2 in the following.
A comment is warranted on the omission of entrainment and Ekman advection in the above model of the ocean mixed layer. Various studies suggest that the observed winter-to-winter memory of the SST tripole might result from the entrainment of temperature anomalies formed the previous winter [e.g., Alexander and Deser, 1995; Watanabe and Kimoto, 2000a; Deser et al., submitted; de Coëtlogon and Frankignoul, submitted]. This effect can be roughly captured in the model by increasing the depth of the ocean mixed layer to its wintertime value. Accordingly, we set $\gamma_{o}=4.10^{8} \mathrm{~J} \mathrm{~m}^{-2} \dot{K}^{-1}$ (100 m mixed layer depth). As discussed by Marshall et al. [2001a] [see also Visbeck et al,, this volume], anomalous Ekman advection further enhances the stochastic forcing of SST anomalies driven by NAO, since anomalies in Ekman and surface turbulent heat fluxes have the same signs north of $30^{\circ} \mathrm{N}$. This could easily be implemented by a term $e T_{a}$ in (3), introducing another parameter $e$, but this does not fundamentally change the results presented below. Accordingly, anomalous Ekman advection will be neglected here.

As a reference system, let us consider a special case of the model (2) through (4) when no SST anomalies are present. This is a climate noise model for the NAO (section 2), as would be found in an atmospheric GCM (AGCM) simulation forced by a climatological mean SST distribution (the limit where the heat capacity of the ocean mixed layer becomes infinite, $\left.\gamma_{o} \rightarrow \infty\right)$. The governing equations for this system are $\gamma_{a} d T_{a}^{C N} / d t=-\left(c \lambda_{s a}+\lambda_{a}\right) T_{a}^{C N}+F_{a}^{C N}$ and $F_{a}^{C N}=\lambda_{s a} N^{C N}$ where the $\stackrel{C}{C} N$ superscript again refers to climate noise, and the primes are omitted for clarity from now on. Taking $N^{C N}$ as a white noise process, the latter two equations predict a red spectrum for $T_{a}^{C N}$ (Figure 5, black thin line) for frequencies higher than $\left(2 \pi \tau_{a}\right)^{-1}$ (indicated by the dashed black vertical line in Figure 5), where $\tau_{a}=\gamma_{a}$ $/\left(c \lambda_{s a}+\lambda_{a}\right)$ is a damping timescale for an NAO circulation anomaly, and a flat spectrum at lower frequency (a first order Markov process with decorrelation timescale $\tau_{a}$ shows an elbow in its power spectrum at frequency $\left(2 \pi \tau_{a}\right)^{-1}$, marking the beginning of the transition from a red (i.e., a sloping straight line on the $\log -\log$ plot) to a white (horizontal line) spectrum. For the parameters used by BB, $\tau_{a}$ is found to be about 5 days. As discussed in section 2 , Feldstein [2000] recently suggested $\tau_{a} \sim 10$ days for the NAO, and we will use this value in the following by doubling the heat capacity of the atmospheric column compared to BB.

Comparing the climate noise spectrum (Figure 5, thin black line) to the model prediction for the power spectrum of $T_{a}$ when SST anomalies are present (Figure 5, thick black line), the latter shows a slightly red spectrum from interan- 
nual to decadal timescales. Both $T_{a}$ and $T_{o}$ (Figure 5, thick grey line) spectra become white at frequencies lower than $\left(2 \pi \tau_{o}\right)^{-1}$, where

$$
\tau_{o}=\frac{\gamma_{o}}{\lambda_{o}+\lambda_{s o}-b c \lambda_{s o} /\left(c+\lambda_{a} / \lambda_{s a}\right)}
$$

is an oceanic damping timescale ( $\tau_{o} \simeq 10$ months for standard parameters). Including the interaction with the upper ocean makes little difference to the total variance of $T_{a}$ (less than $10 \%$ increase), because most of it lies in the high frequency tail of the spectrum. Nevertheless, it substantially increases the $T_{a}$ variance at interannual and longer timescales. In Figure 5, the interannual variance of $T_{a}$ is more than $75 \%$ larger than that of $T_{a}^{C N}$, as the energy levels of the climate noise and model $T_{a}$ spectra differ by a factor 2 to 3 on timescales longer than a few years. This order of magnitude is consistent with that discussed in section 2 .

The red spectrum prediction for SST is commonly found in simple models of middle latitude climate variability [Frankignoul and Hasselmann, 1977] and in observations [e.g., Frankignoul, 1985]. The redness of the atmospheric spectrum at interannual timescales is more surprising and deserves further explanation. Let us write the equation governing the equilibrium or low-frequency (denoted by $L F$ ) amplitude of $T_{a}$, easily obtained by setting time derivatives in (2)-(3) to zero:

$$
\left(\lambda_{s a} c\left[1-b \lambda_{s o} /\left(\lambda_{s o}+\lambda_{o}\right)\right]+\lambda_{a}\right) T_{a}^{L F}=\lambda_{s a} N^{L F}
$$

Similarly, for the climate noise model,

$$
\left(\lambda_{s a} c+\lambda_{a}\right) T_{a}^{C N, L F}=\lambda_{s a} N^{C N, L F}
$$

Equations (6)-(7) indicate that the amplitude of an atmospheric temperature anomaly at low frequency is proportional to the strength of the stochastic forcing, and inversely proportional to that of the net damping. For the standard values used in $\mathrm{BB}(c=1, b=0.5)$, a net damping rate of $15.6 \mathrm{~W} \mathrm{~m}^{-2} \mathrm{~K}^{-1}$ is found in (6), compared with $26.7 \mathrm{~W} \mathrm{~m}^{-2}$ $\mathrm{K}^{-1}$ in (7). For similar levels of stochastic forcing $N$ and $N^{C N}$, the higher energy level found in the spectrum of $T_{a}$ compared to $T_{a}^{C N}$ is thus related to the weaker damping of temperature anomalies found at low frequency. This reduced damping reflects the mutual adjustment of $T_{o}$ and $T_{a}$ which is artificially suppressed in the climate noise model by considering the upper ocean as an infinite heat reservoir $\left(\gamma_{o} \rightarrow \infty\right)$. The degree of adjustment is controlled by the net feedback of SST anomalies onto atmospheric dynamics, the parameter $b$ (see also section 3.2 for further discussion of this issue).

Figure 6 illustrates the sensitivity of BB's model to $b$, by showing $T_{a}$ and $T_{o}$ spectra when $b=-0.5$ instead of $b=0.5$
(Figure 5). Clearly, if the shape of the SST spectrum is essentially unchanged (thick grey line), that of the atmospheric temperature (thick black line) goes from a red to a blue spectrum, with less interannual variance than expected from climate noise (thin black line). The conclusion from Figure 6 is that the reduced thermal damping of oceanic and atmospheric temperature anomalies at low frequency drives the redness of the model NAO spectrum, but it is modified by the strength of the SST feedback. Note that inclusion of ocean dynamics would also modulate the redness of the $T_{a}$ and $T_{o}$ spectra (see section 4).

Modeling studies have given some support for the notion of reduced thermal damping of atmospheric and oceanic anomalies. In a purely atmospheric context, Hendon and Hartman [1982] showed how inclusion of a flow-dependent diabatic heating parameterization could modulate the amplitude of large-scale baroclinic anomalies in a GCM. Manabe and Stouffer [1996], Delworth [1996], and Bhatt et al. [1998] have clearly shown how the variance of surface air temperature was increased when an AGCM was allowed to interact with the upper ocean. Focusing on the NAO, Delworth [1996] and subsequently Bladé [1997] found an increase in NAO variability simulated with the GFDL model when coupled to a slab mixed layer compared to that found when the model is forced by climatological mean SST. Nevertheless, it is not a general rule that an AGCM forced with a climatological mean SST distribution will show a less energetic NAO than when the model atmosphere is free to interact with an ocean model.

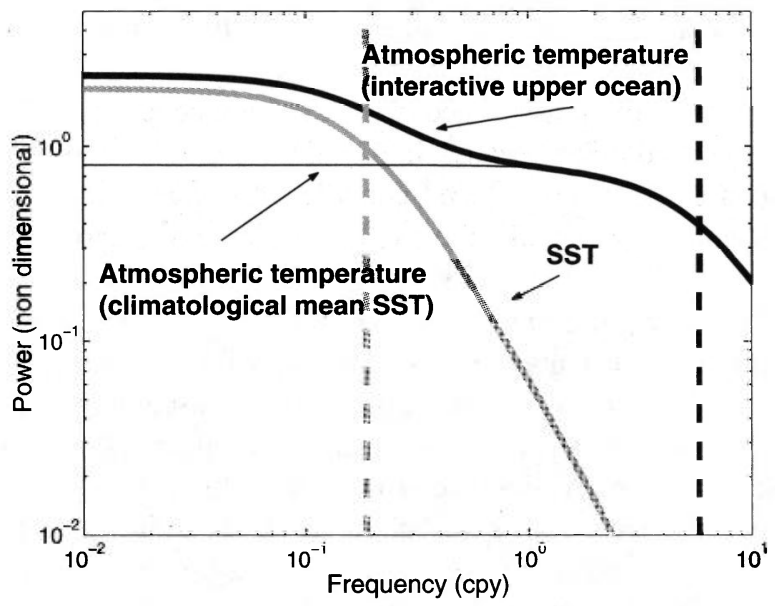

Figure 5. Temperature spectra (black, atmosphere; grey, ocean) predicted by the model of Barsugli and Battisti [1998]. Also indicated is the atmospheric temperature spectrum when no SST anomalies are allowed (thin black line), assuming the same energy level for the stochastic forcings $N$ and $N^{C N}$. The power is non dimensional and the frequency is expressed in cycles per yr. The dashed grey and black vertical lines indicate the frequency $\left(2 \pi \tau_{o}\right)^{-1}$ and $\left(2 \pi \tau_{a}\right)^{-1}$ respectively. 
For instance, Saravanan [1998] found a larger NAO variance in the NCAR Community Climate System Model when forced by SST climatology than when coupled to an oceanic GCM. Robertson [2001] confirms this finding by reporting similar results with the Hamburg climate model. This might again illustrate the importance of the dynamical SST feedback (possibly negative in these cases) in setting the energy level of NAO dynamical spectra. It might also reflect the different mean states and the impact of ocean currents on the upper ocean heat budget (see section 4).

To our knowledge no study has yet focused on testing the reduced thermal damping argument against observations. Some support might nevertheless be found by inspection of observed NAO spectra for geopotential height (Figure 4) or temperature fields (Figure 7, black curve for temperature at $500 \mathrm{mb}$, grey curve for SST) which show a qualitative agreement with those predicted above when a weak positive feedback of SST on the NAO is included (Figure 5 - note that the time series used in Figure 7 were linearly detrended. The redness of the spectra can thus not be attributed to such linear trend). A recent analysis of the persistence time of a low-level vorticity anomaly in the atmosphere by Peña et al. [2001] is also consistent with longer persistence when cold cyclonic anomalies are associated locally with cold SST anomalies (or warm anticyclonic anomalies associated locally with warm SST anomalies), i.e. thermally locked anomalies, but it is not known yet if similar results apply to largescale features like NAO.

\subsection{Mechanisms of SST Feedback in Middle Latitudes}

The dynamics associated with the parameter $b$ in BB's model are complex because, in the real world, they involve the response of the atmosphere to middle latitude as well as tropical and subtropical (the SST tripole) SST anomalies. Although the SST forcings act simultaneously once the SST tripole has been generated, it is useful to separate the mechanisms by which middle and lower latitude SST anomalies interact back on the NAO. Postponing a discussion of the mechanisms associated with the southern lobe of the SST tripole to the next section, we now consider briefly the interactions between mid to high latitude SST anomalies (north of $30^{\circ} \mathrm{N}$ ), atmospheric transient and stationary eddies, and diabatic heating. For a more complete discussion of the dynamics, the reader is referred to Frankignoul [1985] and Kushnir et al. [2002].

At the simplest level, linear theory for an atmosphere with zonal flow having constant vertical shear (or through thermal wind, constant meridional temperature gradient) and static stability $N_{0}$ predicts that the growth rate of the most unstable perturbation is related to the meridional potential temperature gradient $\partial \theta / \partial y$ through

$$
\sigma \simeq 0.31 \frac{\mathrm{g}}{N_{o} \theta_{o}}\left|\frac{\partial \theta}{\partial y}\right|
$$

where $g$ is gravity and $\theta_{0}$ is a reference potential temperature profile [see Gill, 1982; Hoskins, 1983]. As discussed by Hoskins and Valdes [1990], (8) captures the spatial variations of the Northern Hemisphere storm track when the lowlevel $(\sim 780 \mathrm{mb})$ potential temperature gradient is used. Thus, to the extent that SST and air temperature just above the planetary boundary layer are strongly coupled through turbulent air-sea interactions, an enhanced meridional SST gradient is expected to enhance baroclinic wave activity. The SST tripole in a positive NAO index phase [see Visbeck et al., this volume] enhances the meridional temperature gradient close to the U.S. east coast along $45^{\circ} \mathrm{N}$ and reduces it along $30^{\circ} \mathrm{N}$ (Figure 2). It should thus favor more cyclogenesis north of the separated Gulf Stream. Equation (8) also indicates an inverse dependence upon static stability. As has been observed across the Gulf Stream temperature front, warmer waters to the south of the front are associated with more turbulence and lower static stability compared to the conditions found at low levels north of the front [e.g., Sweet et al., 1981]. The influence of SST on the development of unstable baroclinic waves may depend not just on SST gradient, but also on the SST itself. Note that the direct interaction between the SST anomaly and the storm track occurs on short spatial scales, as the anomalous turbulent heat exchange between the ocean and atmosphere will be deter-

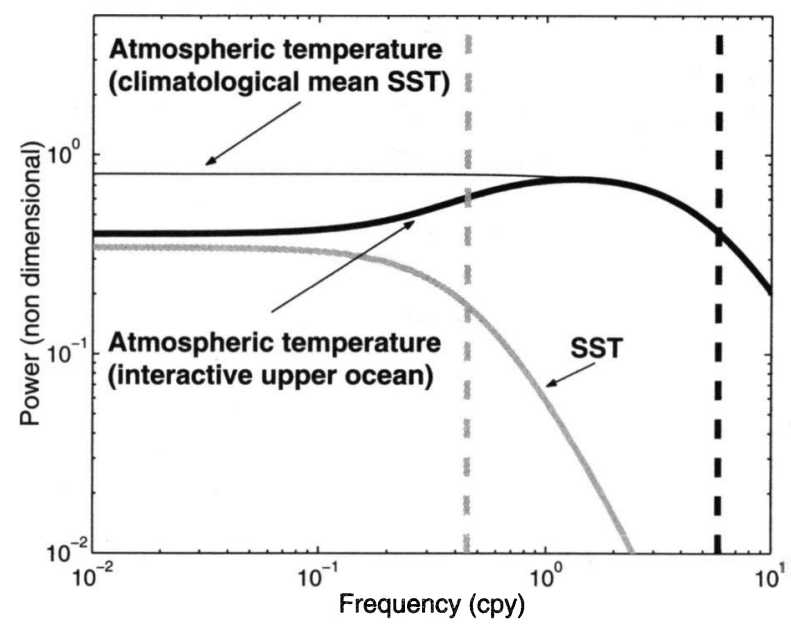

Figure 6. Same as Figure 5 but with $b=-0.5$ instead of 0.5 (negative SST feedback or further away from thermal equilibration). The energy levels can be compared to Figure 5. Note that the timescale $\tau_{o}$ (indicated by the dashed grey vertical line) has shortened compared to Figure 5, in agreement with (5). 
mined by features such as the position of the cold sector and the low-level jet ahead of the cold front [Bresch, 1998]. To resolve this likely requires high resolution models.

The subsequent interaction of the modified storm track with its environment determines if the SST anomaly induces an equivalent barotropic structure like that displayed by the NAO. The modified storm track determines the vertical scale of the heating and cooling associated with positive and negative SST anomalies, by transporting heat and moisture upward [note that changes in radiative forcing associated with anomalous cloud cover, and changes in static stability, might also play a role in determining the vertical structure of the heating. See Kushnir and Held, 1996]. The associated condensational and transient eddy heating may then create a large-scale baroclinic perturbation which can feedback on the storm track, possibly leading to the forcing of equivalent barotropic structure by eddy vorticity fluxes [e.g., Palmer and Sun, 1985; Ting and Peng, 1995; Peng and Whitaker, 1999; Watanabe and Kimoto, 2000b]. It is worth emphasizing that aquaplanet GCMs typically lack such interactions [e.g., Ting, 1991], and even GCMs with zonal asymmetries do not systematically produce equivalent barotropic structures in response to middle latitude SST anomalies [Kushnir and Held, 1996]. Accordingly, predicted atmospheric responses to an anomalous meridional SST gradient along $45^{\circ} \mathrm{N}$ can vary between AGCMs, although a

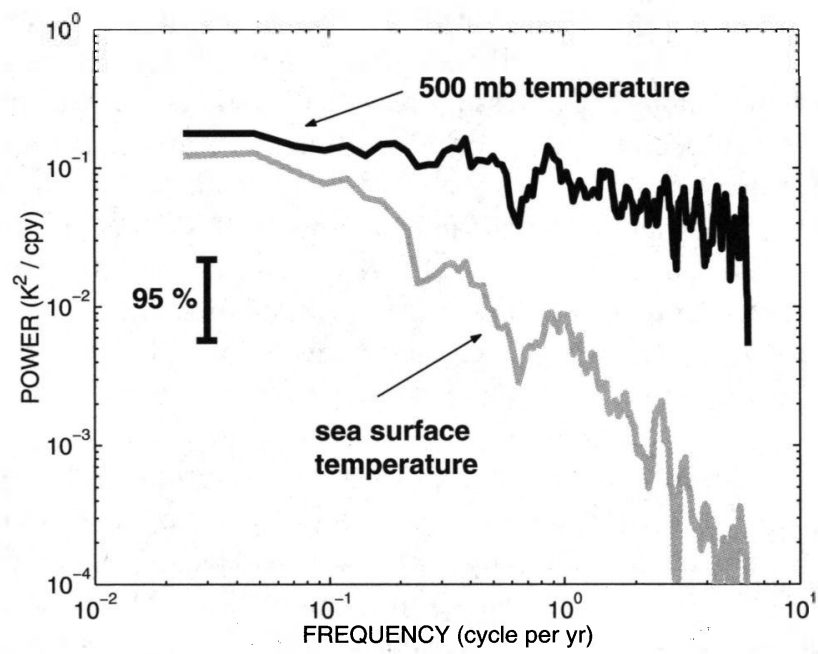

Figure 7. Power spectrum of atmospheric temperature at $500 \mathrm{mb}$ (black) and SST (grey) time series associated with the spatial patterns in Figure 2. The monthly time series were scaled to represent a basin-average amplitude. The frequency is expressed in cycles per $\mathrm{yr}$ (cpy), and the power in $\mathrm{K}^{2} / c p y$. The spectra of the linearly detrended time series were estimated using the multitaper method [Percival and Walden, 1993] with 9 tapers. The vertical bar indicates the $95 \%$ confidence level. strengthening of the westerlies in response to a strengthening of the meridional SST gradient along $45^{\circ} \mathrm{N}$ appears to be robust [e.g., Watanabe and Kimoto, 200b; Sutton et al., 2001; Peng et al., 2002]. This is consistent with a positive feedback on the NAO from the extra-tropical part of the SST tripole, but model studies suggest the feedback amplitude is weak compared to intrinsic variability. A dipolar height anomaly of $20 \mathrm{~m}$ at $500 \mathrm{mb}$ (roughly Icelandic Low minus Azores High) is commonly found for a $1 \mathrm{~K}$ difference across $45^{\circ} \mathrm{N}$ [Robinson et al., 2000; Kushnir et al., 2002].

The above suggests that diabatic heating induced by SST anomalies is sensitive to the state of the atmosphere, and since SST anomalies themselves are to first order created by the atmospheric circulation, there is the possibility of a 'thermally equilibrated' state of the atmosphere and the upper ocean with vanishing diabatic heating. This way of thinking about thermal forcing of the atmosphere was developed by Döos [1962] and subsequently elaborated by Shutts [1987] and Marshall and So [1990; see also the review by Molteni, 1992] in a purely atmospheric context. It is not known from observations if one or both phases of the NAO actually reflect such a thermally equilibrated state, but several theoretical studies have built upon this concept to investigate middle latitude ocean-atmosphere interactions [e.g., Goodman and Marshall, 1999; Goodman, 2001; Ferreira et al., 2001; Nilsson, 2001].

The parameter $b$ in BB's model can be related to thermal equilibration. Neglecting energy storage in the atmosphere (which is a very good approximation on timescales longer than seasonal) and using (4), (2) can be rewritten as

$$
a T_{a}=b T_{o}+N
$$

while the net surface heat flux anomaly (the diabatic heating in BB) can be expressed as

$$
F_{s}^{\prime} \equiv \lambda_{s o}\left[c T_{a}-\left(1+\lambda_{o} / \lambda_{s o}\right) T_{o}\right]=-\lambda_{s o}(d-b c / a) T_{o}+\lambda_{s o} N c / a
$$

where we have introduced the non dimensional parameters $a=c+\lambda_{a} / \lambda_{s a}(=1.12)$ and $d=1+\lambda_{o} / \lambda_{s o}(=1.08)$. At a critical value of $b=a d / \mathrm{c}(=1.2)$, the sensitivity of $F_{s}$ to $T_{o}$ is zero and the model is in a thermally equilibrated regime in the absence of stochastic forcing. For a smaller value of $b$ however, the sensitivity of heat flux to SST (or heat flux feedback) is negative (damping of SST anomalies) although the dynamical feedback can still be positive $(0<b<a d / c)$. It has been suggested that the heat flux feedback could become positive in middle latitudes, implying a strong dynamical SST feedback $b>a d / c$ [e.g., Latif and Barnett, 1994; Grötzner et al., 1998]. This has, however, not been supported by the analysis of the observations, at least over 
the North Atlantic, where a negative heat flux feedback of $20 \mathrm{Wm}^{-2} \mathrm{~K}^{-1}$ is commonly found [Frankignoul et al., 1998; Czaja and Frankignoul, 1999].

\subsection{Mechanisms of SST Feedback in the Tropics}

Our focus in the previous section was on the forcing of the NAO by the SST gradient in the mid-to-high latitude North Atlantic, which is itself a product of intrinsic NAO variability and the ocean circulation. This SST forcing is mediated by the North Atlantic storm track, which distributes the SST induced heating/cooling in the vertical. Here, we consider remote coupling with the tropical Atlantic within an analogous framework. The NAO has a strong impact on the strength and position of convection in the Atlantic intertropical convergence zone [see the review by Marshall et al., 2001b] and even the South American (austral) summer Monsoon system by forcing the southern lobe of the SST tripole [e.g., Robertson and Mechoso, 1998; NoguesPaegle et al., 2000], but also potentially through ocean circulation changes (section 4). At the same time, diabatic heating anomalies over the tropical Atlantic sector can force atmospheric circulation anomalies in the extratropics through changes in the sectorial Hadley circulation and Rossby wave propagation, potentially closing a feedback loop between the NAO and the tropical Atlantic Ocean.

In the zonally-averaged picture, tropical diabatic heating produces a meridional overturning Hadley cell which, for most of the calendar year, extends from deep within the summer hemisphere to the subtropical jet of the winter hemisphere, maintaining the latter through poleward transport of angular momentum. The hypothesis that an intensified Hadley circulation accelerates the subtropical jet and subsequently impacts the middle latitude climate was addressed in idealized experiments by $\mathrm{Hou}$ [1993], $\mathrm{Hou}$ and Molod [1995], Chang [1995], and again more recently by $H o u$ [1998]. Using an idealized GCM with prescribed anomalous diabatic heating in the tropics (zonally symmetric), Hou [1998] argues that a shift of the latter towards the summer hemisphere (dipole in diabatic heating) intensifies the winter hemisphere Hadley cell, and extends the baroclinicity further from the subtropics into middle latitudes. The increased poleward heat transport by more-vigorous low-frequency planetary scale transients was found to lead to middle latitude cooling and high-latitude warming in the winter hemisphere, thus reminiscent of the negative NAO index phase signature on the tropospheric temperature field. For a $6^{\circ}$ southward latitude shift of the diabatic forcing (inducing cooling and warming north and south of the equator, respectively, at a rate of about $0.8 \mathrm{~K} /$ day, i.e., about a $40 \%$ change), the zonally averaged middle latitude response is a $\sim 0.5 \mathrm{~K}$ temperature change at $600 \mathrm{mb}$ and a $\sim 1$ $-2 \mathrm{~ms}^{-1}$ zonal wind change at $250 \mathrm{mb}$. These changes are comparable to the Northern Hemisphere annular mode fluctuations on the monthly timescale [Thompson and Wallace, 2000]. Note however that the relationship between enhanced Hadley circulation and reduced mid to high latitude temperature gradient is dependent upon the latitudinal scale of the convection anomaly that drives the modulation of the Hadley cell. In an experiment where the diabatic heating anomaly was more concentrated in latitude, Hou [1998] found a deceleration of the subtropical jet and enhanced mid to high latitude temperature gradient, projecting partly on positive NAO index conditions.

The above paradigm of a Hadley cell regulating the extratropical climate through tropical axisymmetric diabatic forcing may be more applicable to the Atlantic than the Pacific sector, despite its smaller zonal extent, because, unlike during ENSO events over the Pacific, diabatic heating anomalies tend to be associated with meridional shifts in the Atlantic ITCZ [e.g., Nobre and Shukla, 1996]. Nonetheless, the heating anomalies are zonally localized so that it may be more appropriate to consider their impact on the extratropical rotational flow in terms of forced Rossby wavetrains [Hoskins and Karoly, 1981]. Anomalous descent over a cold SST anomaly in the subtropical North Atlantic is associated with a convergence and anomalous cyclonic vorticity at upper levels. This positive Rossby wave source can excite a northward propagating wavetrain with expected anomalous high pressure over the central north Atlantic (thus projecting partly on a positive NAO index phase). Similar mechanisms may also apply to south Atlantic SST forcing, where a warm anomaly over $40^{\circ} \mathrm{S}-10^{\circ} \mathrm{N}$, in an AGCM study, was shown by Robertson et al. [2000] to induce a southward shift of the mean regional Hadley cell, producing an upper-level convergence anomaly over the Caribbean and subsequent ridging over the central North Atlantic.

Idealized experiments with a low resolution GCM by Okumura et al. [2001] indicate typically a tripolar geopotential height anomaly (centers of action at about $15^{\circ}-45^{\circ}-65^{\circ} \mathrm{N}$ ) of about $10 \mathrm{~m}$ amplitude at $500 \mathrm{mb}$ for a change of $1 \mathrm{~K}$ in the cross-equatorial SST gradient (either induced by north or south off-equatorial SST anomalies, or both in the form of a SST dipole), with a hint at a stronger impact on the 'Azores High' than on the 'Icelandic Low' region. The response is robust and also seen in higher resolution GCMs [e.g., Terray and Cassou, submitted]. The NAO sensitivity to the southern lobe of the tripole appears thus of similar strength and sign (positive feedback) to that found in GCMs forced with its middle latitude part (mid to 
high latitude SST gradient change - see section 3.2).

Two comments are warranted on the above forced Rossby wave mechanism. First, as discussed by Sardeshmukh and Hoskins [1988], the relationship between the Rossby wave source and the anomalous diabatic heating is not simple. Due to the advection of vorticity by the divergent component of the flow, the region that acts as a source of Rossby waves in the presence of tropical heating does not generally coincide with the region where the heating takes place. In fact, the largest Rossby wave sources are typically in the subtropics, rather than the Tropics, because of the much stronger vorticity gradients in the vicinity of the subtropical jet. The local Hadley circulation and Rossby wave sources are thus intimately connected. Second, the interaction of the propagating Rossby wavetrain with middle latitude transient eddies ultimately shape the net response of the Northern Hemisphere to the tropical forcing [Hoskins and Sardeshmukh, 1987; Held et al., 1989; Hoerling and Ting, 1994]. An illustration of this in the context of NAO/tropical Atlantic interactions can be found in, for instance, Watanabe and Kimoto [1999], Sutton et al. [2001] and Terray and Cassou [submitted].

\subsection{SST Impact on NAO in Observations}

In support of the mechanisms proposed in sections 3.2 and 3.3, many AGCM studies suggest a positive feedback between the SST tripole as a whole and the NAO [Venzke et al., 1999; Rodwell et al., 1999; Watanabe and Kimoto, 2000b; Cassou and Terray, 2001a; Sutton et al., 2001; Terray and Cassou, submitted; Peng et al., 2002], although not all [Robertson, 2001]. Analysis of the observational record should thus at least provide a hint for such a feedback.

A major problem, however, arises when considering observational studies. Indeed, the fact that the atmosphere predominantly forces middle latitude SST anomalies makes it difficult to estimate directly the SST feedback on the atmosphere (for a review of the literature on the empirical and theoretical estimates of the SST feedback prior to the 1990s, see Frankignoul [1985]). Since the work of Davis [1976] and Frankignoul and Hasselmann [1977], the study of the temporal covariance or correlation between SST anomalies and various tropospheric variables in lead and lag conditions has nevertheless appeared as a useful tool to bypass this problem [Frankignoul, 1985; Deser and Timlin, 1997; Czaja and Frankignoul, 1999; 2002]. The rationale for this statistical approach can be understood from the model developed in section 3.1. Consider the linear decomposition of NAO variability as in (9) at time $t$, and multiply by $T_{o}(t-\tau)$, i.e. by the SST anomaly at a previous time $t-$ $\tau$. Taking an ensemble average (denoted by a bracket) yields

$$
a\left\langle T_{o}(t-\tau) T_{a}(t)\right\rangle=b\left\langle T_{o}(t-\tau) T_{o}(t)\right\rangle+\left\langle T_{o}(t-\tau) N(t)\right\rangle
$$

so that if $\tau$ is larger than the decorrelation time of $N$ (typically a couple of weeks), then $\left\langle T_{o}(t-\tau) N(t)\right\rangle \simeq 0$ and we get the simple relation

$$
a\left\langle T_{o}(t-\tau) T_{a}(t)\right\rangle \simeq b\left\langle T_{o}(t-\tau) T_{o}(t)\right\rangle \text { for } \tau>1 \text { month }
$$

The latter equation indicates that the strength of the covariance between SST and an atmospheric variable when SST leads is proportional to the dynamical feedback $b$, with the stronger the feedback, the larger the covariance when SST leads. It is important to emphasize that (10) was obtained by assuming an instantaneous impact of SST onto the atmosphere (storage was neglected in (9)). A non-null covariance when SST leads by, say, $\tau$ months should thus not be interpreted as a delayed response of the atmosphere to SST by $\tau$ months. It simply reflects that atmospheric variability has an SST induced component that has the persistence of the SST anomaly ( $\tau_{o}$ in the model of section 3.1). This persistence ultimately determines the lag over which (10) is useful, since we expect the covariance $\left\langle T_{o}(t-\tau) T_{o}(t)\right\rangle$ to become negligible when is larger than the SST persistence time. Note also that in practice, we always expect nonnull covariance $\left\langle T_{o}(t-\tau) T_{a}(t)\right\rangle$ because of the finite length of the observational record. Statistical significance tests are thus needed to estimate the level of covariance that could arise by chance in the observations [Monte Carlo simulations are traditionally used, e.g., von Storch and Zwiers, 1999].

Figure 8 from Czaja and Frankignoul [2002] illustrates this technique, and shows the dominant patterns of covariability between monthly SST (shaded) and $500 \mathrm{mb}$ geopotential height (contoured every $5 \mathrm{~m}$ ) anomalies over the North Atlantic sector in the NCEP/NCAR reanalysis [Kalnay et al., 1996], as a function of time lag. The analysis was applied for several lags, ranging from SST lags by one month (upper left, $L=1$ on the figure) to SST leads by 7 months (lower right corner, $L=-7$ on the figure). One observes a robust dipolar pattern in the height field at all lags, which is reminiscent of the NAO signature on pressure. On the other hand, the SST pattern evolves somewhat from SST lags to SST leads. At zero lag and when SST lags the height field we recover the familiar SST tripole pattern (Figure 2), as found in many studies [Wallace et al., 1990; Deser and Timlin, 1997]. When SST leads the height field by up to seven months, we observe a large-scale SST pattern with opposite signed anomalies southeast of 


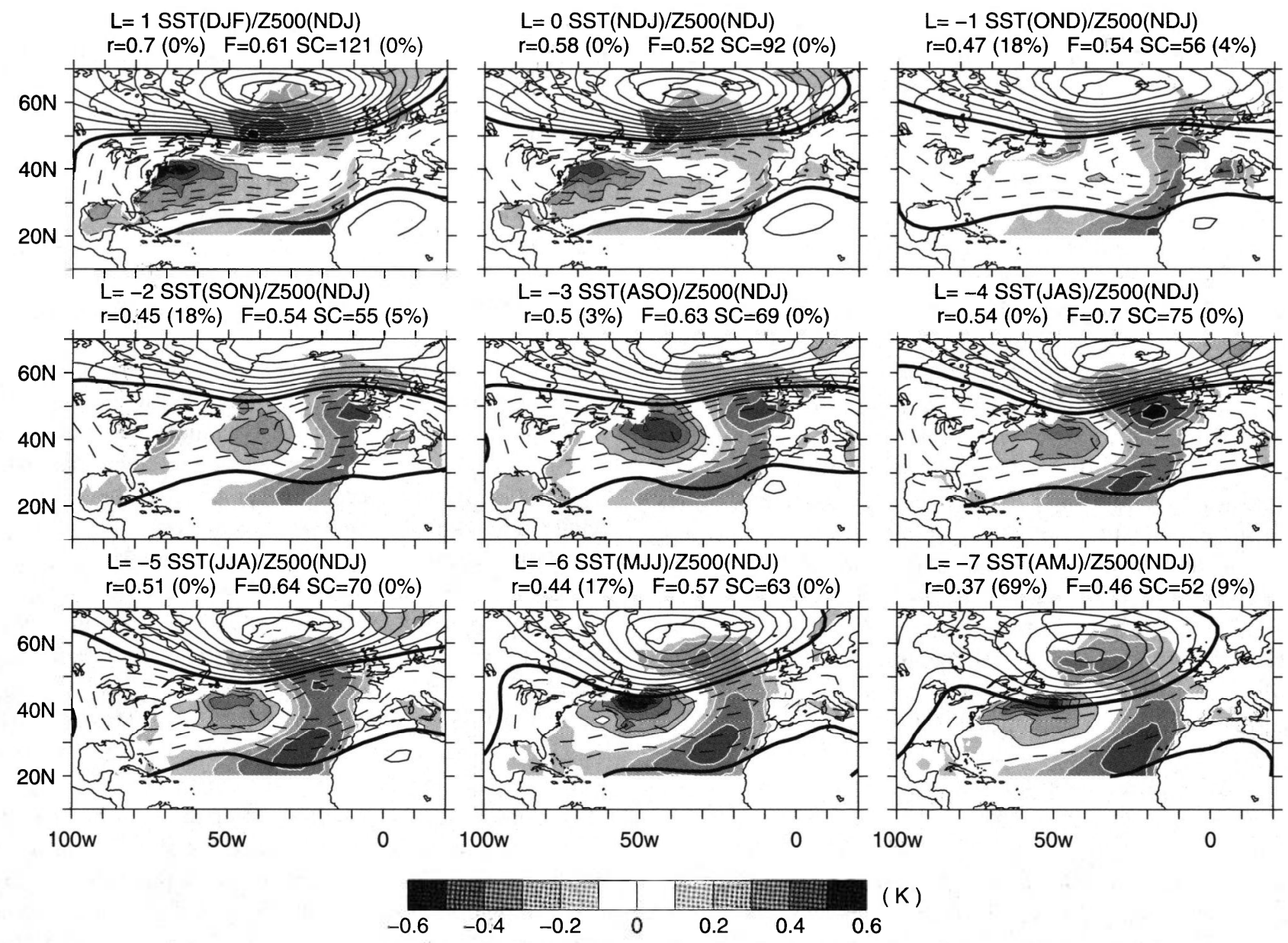

Figure 8. Dominant patterns of covariability between monthly SST (in $K$, shaded with white contours when positive) and $500 \mathrm{mb}$ height (contoured every $5 \mathrm{~m}$, continuous when positive) anomalies. The height field is fixed to November through January and the SST field lagged accordingly by $L$ months, as indicated on the plot (SST leads when $L<0$ ). Also indicated are the temporal correlation coefficient $r$, the fraction of squared covariance $F$ explained by the patterns, and their squared covariance $S C$. The number in parenthesis indicates a significance level (percentage of chance that the observed covariance arise by chance), as deduced from Monte Carlo simulations. From Czaja and Frankignoul [2002].

Newfoundland and along the eastern North Atlantic, in the form of a horseshoe pattern (hereafter NAH, for North Atlantic horseshoe). The signs are such that anomalously cold SST southeast of Newfoundland and anomalously warm SST along the eastern boundary of the Atlantic precede a negative NAO index phase by several months [Czaja and Frankignoul, 1999; Drévillon et al., 2001]. Although the projection between the NAH and the tripole SST patterns is not perfect $(\sim 0.6)$, the two patterns share common features (reduced meridional SST gradient along $40^{\circ} \mathrm{N}$ and enhanced meridional SST gradient along $30^{\circ} \mathrm{N}$ ). Figure 8 is thus consistent with (10) and is suggestive of a non zero feedback of the SST tripole onto the NAO. Since the NAO generates the same polarity of the tripole as that found when the tripole leads the NAO, the feedback is positive. It must be emphasized that the interpretation of Figure 8 is delicate. As suggested by one reviewer, one could also argue that Figure 8 reflects a winter-to-winter memory of the NAO (yet to be explained) in addition to a winter to summer memory in the SST tripole. Further discussion of the interpretation of Figure 8 (e.g., impact of tropical SST anomalies, seasonal effects) can be found in Czaja and Frankignoul [2002]. As shown in Drévillon et al. [2001], changes in baroclinicity and transient eddy activity are consistent with changes in meridional SST gradient associated with the NAH and the SST tripole patterns. This suggests that a direct interaction between anomalous SST and the storm track, as discussed in section 3.2, could be responsible for the oceanic influence suggested by Figure 8. 
The fraction of monthly NAO variance explained by the positive feedback is, however, weak - no more than $15 \%$ [Czaja and Frankignoul, 2002] - consistent with the results gained from the simple model in section 3.1. The fraction of interannual variance that might be explained by this feedback is related to the deviation from white noise displayed by the NAO indices spectra (e.g., Figure 7). As discussed in sections 2 and 3.1, it might reach $60 \%$.

\subsection{Summary}

We have discussed the relevance of Atlantic air-sea interactions as a source of enhanced NAO variability in the absence of ocean dynamics in a hierarchy of models and in observations. It was shown how local reduced thermal damping of atmospheric and oceanic temperature anomalies on timescales longer than that set by the thermal inertia of the mixed layer (a few months) will tend to redden dynamical NAO spectra compared to those of climate noise (section 2). This effect is strongly dependent upon a nonlocal dynamical impact of the SST tripole onto the NAO, which seems to be supported (for both its northern centers of action and its southern lobe) by several observational and modeling studies.

There is still however a large spread in modeling studies of the SST tripole-NAO interactions. This spread probably reflects the complexity of the mechanisms involved both in middle latitudes and the subtropics. Quantitatively, the impact of air-sea interactions on the NAO appears weak compared to the level of NAO variability intrinsically generated by the atmosphere. It is also dependent upon timescales, the impact significantly increasing with longer timescales. An indication that ocean dynamics might introduce further modifications to the climate noise scenario is studied in the next section.

\section{THE NORTH ATLANTIC OCEAN AS A HEAT CARRIER}

Based on the analysis of the historical record (roughly 1900 to present) of surface variables like SST, atmospheric pressure and winds [the COADS dataset, Woodruff et al., 1987] two climate signals potentially involving an active role for ocean circulation have been identified in the observations. Both show NAO-like anomalous surface circulation in the atmosphere, but have distinct timescales: decadal and interdecadal. Encouragingly, the variability described in some coupled atmosphere-ocean models bears some resemblance to that seen in observations and provides more readily available diagnostics and analysis to infer potential mechanisms.

To review the observational and model results, we have chosen to first discuss the impact of ocean heat transport changes at the intergyre boundary of the North Atlantic on the NAO. The idea of interacting ocean gyres and the NAO is indeed a dominant paradigm in the field, especially at decadal timescales (section 4.1). We will then examine NAO variability involving basin scale changes in ocean heat transport associated with the MOC and, in general, longer (interdecadal) timescales (section 4.2). We conclude with a summary in section 4.3.

\subsection{NAO/Ocean Circulation Interaction at the Intergyre Boundary}

A major climatological feature of the North Atlantic ocean is the region of sharp SST gradient marking the separation of the subtropical and subpolar gyres and the path of the separated Gulf Stream (or simply the North Atlantic current). It was emphasized in section 3 that the NAO may be sensitive to such a meridional SST gradient; through storm track dynamics, but the SST gradient at the intergyre boundary itself is also modulated by the ocean circulation, especially at timescales longer than a few years [e.g., Bjerknes, 1964; Battisti et al., 1995; Halliwell, 1998]. This yields the possibility of coupled ocean-atmosphere dynamics driven in the vicinity of the intergyre boundary.

It has been suggested in many studies that the enhanced variability displayed by the SST tripole in the decadal band [Deser and Blackmon, 1993; Sutton and Allen, 1997; Moron et al., 1998; Tourre et al., 1999; Czaja and Marshall, 2001; Costa and Colin de Verdière, 2002] might reflect such oceanic impact. As a simple illustration, we show in Figure 9 a composite map for SST anomalies based on a long time series of the SST difference $(\Delta T)$ across the separated Gulf Stream $\left(\left[60^{\circ}-40^{\circ} \mathrm{W} / 40^{\circ}-55^{\circ} \mathrm{N}\right]\right.$ minus $\left[80^{\circ}-60^{\circ} \mathrm{W} / 25^{\circ}-\right.$ $\left.\left.35^{\circ} \mathrm{N}\right]\right)$. This index captures the SST tripole, with anomalously warm SST north of the separated Gulf Stream and in the eastern subtropics, but anomalously cold conditions south of the stream $(\Delta T>0)$. The composite maps reveal that the tripole persists from one year to the next (not shown), but essentially disappears after three years. This is expected if the thermal inertia of the upper ocean is the only mechanism introducing a timescale for the tripole (see section 3.1). Strikingly however, the tripole reappears after six years with opposite signs, indicating a damped oscillation at decadal timescale rather than a simple exponential decay.

Before addressing which ocean processes could be responsible for this behavior of the SST tripole, it is worth investigating if similar features are present in atmospheric variables. The various dynamical NAO indices presented in this chapter exhibit little indication of such a preferred decadal timescale, partly because of the poor frequency res- 
olution associated with the short record used (40 years in Figures 4,7 ). Analyses of longer records give a weak indication that a decadal enhancement of power is present in atmospheric variables [e.g., surface winds and sea level pressure for Deser and Blackmon, 1993; sea level pressure for Tourre et al., 1999; Robertson, 2001]. Figure 10 is an illustration using the reconstructed sea level pressure (SLP) field from Kaplan et al. [2000]. It displays the power spectrum of SLP anomalies averaged over the Greenland-Icelandic Low region (black), the northern center of action of the NAO signature in SLP. It shows enhanced variance in the 10-20 year band and reduced power at longer timescales. It is striking that similar spectral signatures are found independently in the $\Delta T$ index (Figure 10, grey) with both indices keeping significant coherence at decadal and longer timescales [Czaja and Marshall, 2001]. This might reflect a modulation of the Greenland-Icelandic Low by the ocean circulation at decadal and longer timescales, through changes in heat transport across the mean position of the separated Gulf Stream (see below). Alternatively, one can argue that the observed deviations from white SLP spectra are not significant and that the coherence between Greenland-Iceland SLP and SST gradient anomalies at low frequencies just reflects the driving of the latter by the former on much shorter timescales (the climate noise interpretation).

Both mean and anomalous ocean currents could be instrumental in setting a preferred decadal timescale to NAO-SST tripole interactions, through their impact on the meridional SST gradient at the intergyre boundary. Consider first the advection of the anomalous middle latitude SST dipole (the two northern centers of action of the SST tripole) by the mean meridional circulation (Figure 11). At a timescale determined by the meridional scale of the NAO forcing $L$ and the mean current velocity $V$, advection and surface forcing can reinforce each other, leading (if damping effects are not too strong) to enhanced power in the SST dipole and possibly NAO-circulation anomalies for sufficiently strong SST feedback [Saravanan and McWilliams, 1998; see also Visbeck et al., 1998; Krahman et al., 2001; Drijfhout et al., 2001; Visbeck et al., this volume]. For $L=5000 \mathrm{~km}$ and $V$ $=1-2 \mathrm{~cm} \mathrm{~s}^{-1}$, this "resonant timescale" is of order of 10 years, roughly consistent with the damped oscillation timescale seen in Figure 9. Note that it would not exist independently in the ocean and the atmosphere but arises only when the two fluids are considered together.

Another possible explanation involves changes in ocean circulation rather than mean currents. Indeed, the subtropical-subpolar gyres of the North Atlantic and the Gulf Stream-recirculation system strongly respond to NAO variability [Taylor and Stephens, 1998; Joyce et al., 2000; Curry and McCartney, 2001; Frankignoul et al., 2001b; Visbeck et al., this volume], but also show significant intrinsic variability of their own on interannual and longer timescales [e.g., Jiang et al., 1995; Meacham, 2000; Cessi and Primeau, 2001; Cessi and Paparella, 2001; Dewar, 2001]. Both intrinsic and forced dynamics lead to changes in heat transport across the mean path of the separated Gulf Stream through expansion - contraction of the gyres, or equivalently, through large-scale anomalous currents acting on mean temperature gradients. The forced response of the thermocline-ocean mixed layer to large-scale wind forcing orchestrated by the atmosphere and its subsequent feedback on the atmospheric flow has been studied in a hierarchy of idealized coupled models [e.g., Jin, 1997; Münnich et al., 1998; Neelin and Weng, 1999; Cessi, 2000; Primeau and Cessi, 2001; Marshall et al., 2001a], in the lines of the scenario put forward by Latif and Barnett [1994; 1996] for the North Pacific. Similarly, the buoyancy forcing of the ocean driven by the NAO through its impact on Labrador Sea convection, and its possible subsequent feedback on the NAO through changes in the path of the separated Gulf Stream has been studied in observations and a simple model by Joyce et al. [2000]. These studies can generally be understood in a forced delayed oscillator framework, as widely used for ENSO, with the ocean circulation providing the delay (typically set by the propagation time of long Rossby waves across the North Atlantic - from 5 to 10 years, depending on latitude - or set by advection, again typically 5 to 10 years for subpolar-subtropical gyre exchange), and intrinsic NAO variability the source of stochastic forcing (Figure 12). Although some realistic atmosphere-ocean GCMs support this type of active coupling between anomalous ocean gyres and the NAO [e.g., Grötzner et al., 1998], it must be emphasized that not all coupled GCMs show this behavior over the North Atlantic. Rather, some exhibit a purely passive oceanic response to unaltered NAO variability [e.g., Zorita and Frankignoul, 1997; Frankignoul et al., 2001a], even when idealized in their settings [e.g., Kravtsov and Robertson, 2002]. As discussed by Latif [1998], this might reflect the different sensitivity to SST of the atmospheric component of the coupled models. It may also reflect differences in the mean oceanic and atmospheric states simulated, since the latter may impact the models' ability to represent anomalous ocean heat transport and its influence on the NAO.

It is interesting to observe a reduced energy level in SST or SLP at low frequency (Figure 10) whereas an enhanced energy level was predicted in the absence of ocean dynamics (section 3.1). This might be understood as an additional damping effect introduced by the ocean circulation on lowfrequency oceanic and atmospheric temperature anomalies. In the illustrative model of anomalous ocean current devel- 
TN - TS (Feb-March-Apr)
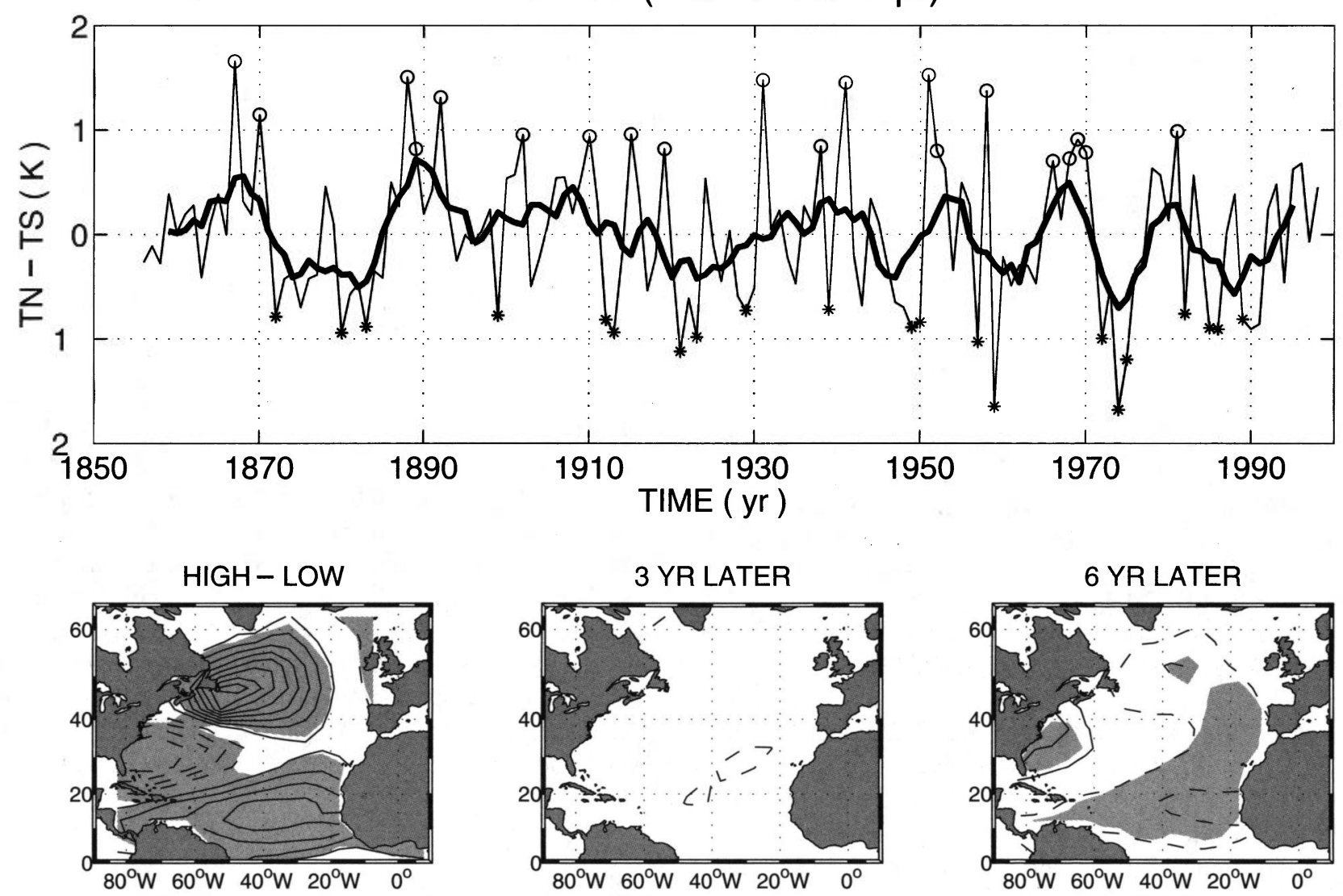

Figure 9. (upper panel) Time series of the cross Gulf Stream SST index $\Delta T$ (in $K$, February through April averaged, raw time series thin, 6-yr running mean thick). (bottom panel) Composite maps for SST anomalies, based on years where the $\Delta T$ index is high and low, as indicated by the circles and stars in the upper panel. The left panel indicates the large-scale SST anomalies associated simultaneously with $\Delta T>0$, while the middle and right panels indicate the SST anomalies 3 years and 6 years after strong $\Delta T>0$ events. The SST anomalies are contoured every $0.2 \mathrm{~K}$ (dashed when negative), and the shading indicates where the composites are significant within the $95 \%$ confidence level, as deduced from a Student $t$ test. All SST data are from Kaplan et al. [1997]. From Czaja and Marshall [2001].

oped by Marshall et al. [2001a], anomalous ocean heat transport is directed from the warm to the cold anomaly at timescales longer than the oceanic adjustment time to NAO wind forcing. It thus acts on SST as an anomalous down gradient heat flux at these timescales [Czaja and Marshall, 2001; Figure 12]. A similar feature is found when considering the role of mean advection in the model of Saravanan and McWilliams [1998], with atmospheric and oceanic temperature anomalies in spatial quadrature for sufficiently strong advection and long timescales, thus 'pulled away' from thermal equilibration by ocean currents (not shown).

It is certainly an oversimplification to attribute the bulk of the decadal variability displayed by the tripole to air-sea interactions in the vicinity of the intergyre boundary alone. Indeed, an alternative explanation has been invoked, where the decadal timescale is driven from the tropical Atlantic through local unstable air-sea interactions [Chang et al., 1997]. In this scenario, tropical Atlantic variability would then remotely impact the middle latitude centers of action of the SST tripole [Okumura et al., 2001] and the NAO (section 3.3). Some observational support for this hypothesis exists. Rajagopalan et al. [1998; see also Tourre et al., 1999] found evidence of a significant coherence on decadal timescales between tropical Atlantic SSTs and the NAO signature in SLP (Icelandic low and Azores high). Both the northern $\left(5^{\circ} \mathrm{N}-20^{\circ} \mathrm{N}\right)$ and the southern $\left(5^{\circ} \mathrm{S}-15^{\circ} \mathrm{S}\right) \mathrm{SST}$ anomalies are involved, as is their difference (the Atlantic cross-equatorial SST index), with signs consistent with the remote forcing discussed earlier (section 3.3). Nevertheless, the coherence may also reflect a passive response of the 


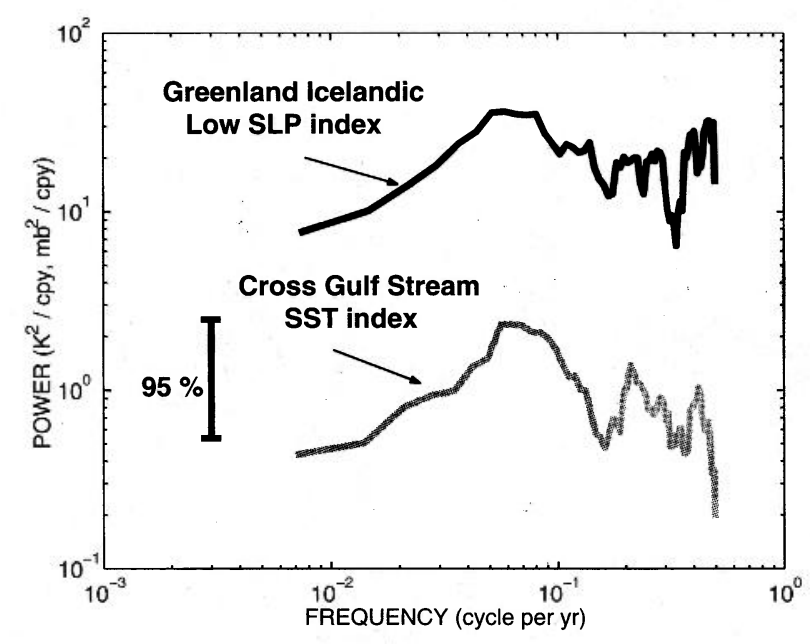

Figure 10. Power spectrum of Greenland Icelandic Low SLP (black) and cross Gulf Stream SST index (grey), both averaged in late winter (February through April) based on the data from Kaplan et al. [1997; 2000]. The frequency is expressed in cycles per year (cpy) and the power in $\mathrm{K}^{2} / c p y$ and $\mathrm{mb}^{2} / c p y$ for SST and SLP respectively. From Czaja and Marshall [2001].

large-scale Atlantic cross equatorial SST gradient to NAO forcing, either through local air-sea interactions in the tropical Atlantic connecting the two hemispheres [Xie and Tanimoto, 1998], or through basin-scale changes in meridional overturning [Yang, 1999]. The latter are further discussed in the next section.

\subsection{NAO/Ocean Circulation Interaction on a Basin-Scale}

Various coupled GCMs or ocean only integrations have shown substantial variability of the MOC at interdecadal timescales, with associated current, temperature and salinity anomalies extending all the way to the equator [e.g., Delworth et al., 1993; Timmerman et al., 1998; Häkkinen, 1999; Eden and Willebrandt, 2001; Eden and Jung, 2001; Dong and Sutton, 2001]. The dynamics of such basin-scale changes were discussed in detail in Visbeck et al. [this volume]. They involve tropical extra-tropical oceanic teleconnections set rapidly (months) by boundary Kelvin waves [e.g., Kawase, 1987; Johnson and Marshall, 2002] as a response to changes in the rate of deep-water formation at high latitudes, and the subsequent generation of long planetary Rossby waves along the eastern boundary of the North and South Atlantic [Wajowicz, 1986]. Further delay between changes in buoyancy forcing at high latitudes and oceanic changes elsewhere might also be introduced by oceanic advection and storage [e.g., Marotzke and Klinger, 2000]. The possibility that changes in meridional oceanic heat transport might be actively involved in (not simply respond- ing to) the observed interdecadal NAO variability is examined below.

Bjerknes first documented significant basin-scale changes in SST over the North Atlantic on interdecadal timescales. In his 1958 paper, he describes a warming of the North Atlantic from the late nineteenth century to the 1920-1930s. He found the warming to be most pronounced $\left(2{ }^{\circ} \mathrm{C}\right.$ in SST) along the axis of the separated Gulf Stream and its extension into the interior. A similar spatial pattern of anomalous SST and surface air temperature was later shown by Deser and Blackmon [1993] to dominate the variability of these fields in the twentieth century (Figure 13b,c), with the warming trend observed by Bjerknes followed by a cooling trend from the 1940 s to the 1970s, and a subsequent warming trend from the 1970 s to the 1990 s. Similar results were reported by Kushnir [1994], although his SST maps have a larger basinwide scale and do not show a pronounced warming along the path of the North Atlantic current. These SST anomalies are associated with sea surface salinity (SSS) anomalies of the same sign [Levitus, 1989]. Based on the analysis of various proxy data, Mann et al. [1998] and Delworth and Mann [2000] argue that this approximately 70-year climate oscillation, sometimes called the Atlantic Multidecadal Oscillation [Kerr, 2000], has occurred over past centuries as well.

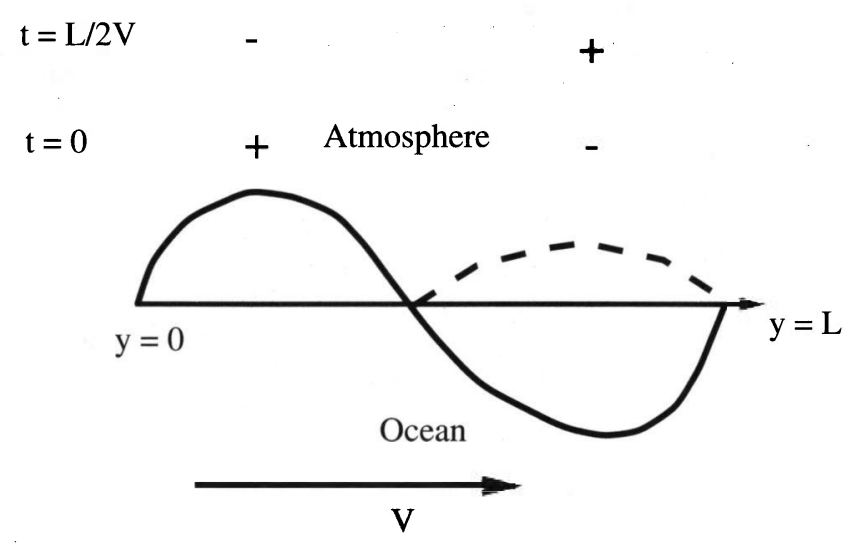

Figure 11. Schematic of ocean-atmosphere interactions occurring in presence of a mean oceanic velocity $V$ and a dipolar surface NAO forcing of meridional scale $L$. The mean current advects the initial dipole (thick continuous line) northward once it has been generated through NAO surface forcing at $t=0$ (the sign of the forcing is indicated by the plus-minus signs). At $t=L / 2 V$, the SST anomaly has thus become that shown in thick dashed line, if damping if not too strong. Of all timescales associated with the climate noise NAO forcing, that corresponding to $L V$ will reinforce this SST anomaly at $t=L / 2 V$, as indicated by the change of signs in the forcing. This leads to enhanced variance of the SST dipole and NAO near the 'advective resonant timescale' $L / V$. From Saravanan and McWilliams [1998]. 
A striking feature of Figure 13 is that the SST anomalies do not seem to be a local response to changes in windstress as commonly found on shorter timescales. Rather, they are found well upstream of the dominant surface wind changes. In addition, for a warming along the separated Gulf Stream, an anomalous cyclonic circulation centered at $40^{\circ} \mathrm{N}$ is observed, with reduced westerlies and trade winds to the north and south respectively. Such weakening of the winds favors the development of a negative SST anomaly along the Gulf Stream extension, as a result of the weakening of the subtropical gyre, rather than a positive SST anomaly as observed. This may be an indication that the MOC, rather than the atmosphere, is driving the basin-scale warming and cooling at these long timescales. The SST pattern (Figure 13b) might reflect the local convergence of ocean heat transport between $30-50^{\circ} \mathrm{N}$, with the associated warming of the atmosphere inducing a downstream low pressure anomaly at the surface (but see below for a cautionary note on this type of interpretation), as found in simple linear baroclinic models of the tropospheric response to heating [Hoskins and Karoly, 1981].

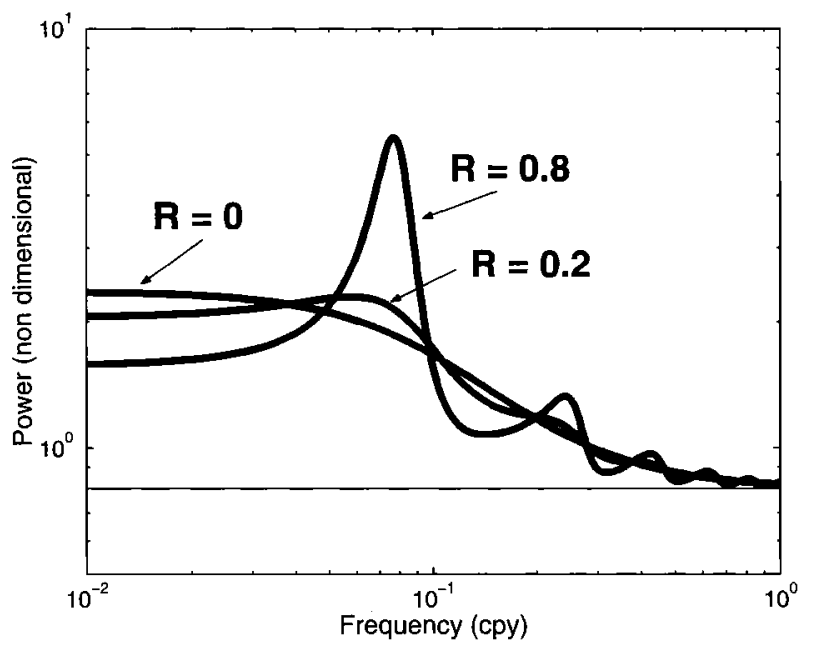

Figure 12. Surface wind $\tau$ (or atmospheric temperature) spectra from the delayed oscillator model of Marshall et al. [2001a]: $\tau=N-f T_{o}$ and $d T_{o} / d t=-\lambda T_{o}-R \lambda T_{o}\left(t-t_{d} / 2\right)-\alpha N$ where $N$ is a stochastic forcing, $\alpha$ a scaling constant, $R$ measures the strength of anomalous ocean heat transport, $T_{o}$ is SST, $f$ is the strength of the SST feedback on the surface winds, and $\lambda$ measures local damping of SST anomalies through air-sea interactions. The spectrum for $\tau$ is given for various choices of $R$ (weak and strong impact of ocean heat transport, as indicated on the plot). The thin continuous line indicates the climate noise spectrum $(\tau=N)$, while the limit of no ocean dynamics $(R=0)$ is another version of the 'reduced thermal damping' spectrum of Figure 5 (thick black line). Note the reduced energy level at long timescales, as the strength of the ocean circulation increases. The frequency is expressed in cycles per year. The delay timescale $t_{d}$ was set to $t_{d}=10$ years. Other parameters are taken from Czaja and Marshall [2000].
Kushnir [1994] also found this SST/sea level pressure association for the subsequent cooling period (1970-1984 minus 1950-1964), with anomalous high pressure along $45^{\circ} \mathrm{N}$. Interestingly, Bjerknes' [1958] map for the earlier warming trend (1925-1932 minus 1890-1897) shows anomalously warm SST associated with positive pressure anomalies in middle latitudes, i.e. opposite to that of Deser and Blackmon [1993] and Kushnir [1994], but similar to the pressure response found in the coupled simulations of Timmermann et al. [1998; Figure 14] and Delworth et al. [1993]. These disparities reflect the difficulties of inferring ocean and atmospheric dynamics soley from analysis of observations. Recent numerical experiments by Sutton and Mathieu [submitted] and D'Andréa et al. [in preparation] further emphasize this limitation. They show that the atmosphere/slab ocean mixed layer model response to a prescribed oceanic heat flux convergence along the separated Gulf Stream displays only small equilibrium SST anomalies over the region of oceanic forcing. We will come back to this important issue later. Note also that the composite analysis in Figure 13, although using decadal averages separated by more than a decade, does not ensure that the ocean and atmosphere are in dynamical equilibrium, making even more difficult a dynamical interpretation.

As mentioned earlier, Delworth et al. [1993] and Delworth and Mann [2000] describe large variations of the overturning circulation in the GFDL R15 coupled model at timescales of about $50 \mathrm{yr}$, which have anomalous SST and SSS patterns similar to those seen in observations [Kushnir, 1994; Levitus, 1989], i.e. of similar sign over the North Atlantic basin. In the GFDL model, the MOC variability was interpreted as a damped oscillation sustained by stochastic atmospheric forcing [Griffies and Tziperman, 1995; Delworth and Greatbatch, 2000], as was also proposed by Selten et al. [1999] and Saravanan et al. [2000] in simpler coupled ocean-atmosphere models. This type of oscillation was found recently to emerge through a linear unstable mode of the ocean circulation [Huck and Vallis, 2001; te Raa and Dijkstra, 2002], a form of longwave baroclinic instability setting the interdecadal timescale [Colin de Verdière and Huck, 1999; Huck et al., 2001]. Thus, although stochastic atmospheric forcing is important in sustaining the interdecadal variability of the MOC in the GFDL simulation, active coupling with the atmosphere is not crucial. Nevertheless, as the MOC strengthens and drives basin-scale warming of the North Atlantic, the GFDL model atmosphere shows a weak tendency to go preferentially towards a positive NAO index phase.

A more fundamentally coupled mechanism was proposed by Timmermann et al. [1998] to describe the interdecadal variability in the ECHAM3/LSG simulation, involving changes in the MOC on periods around 35 years. Although its signature in SST, SSS and SLP resembles that of 

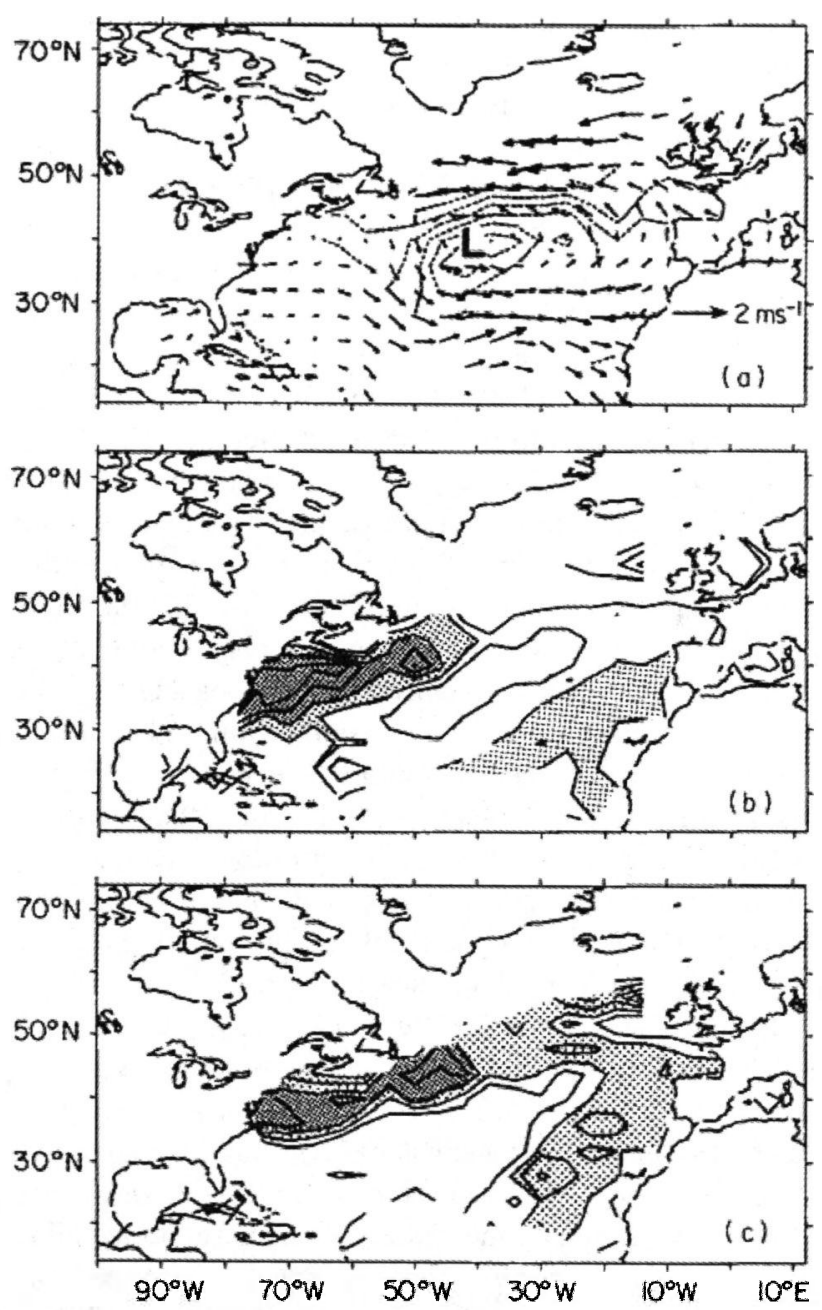

Figure 13. Difference between the periods 1939-1968 and 1900-1929 of winter (a) sea level pressure and wind, (b) SST, and (c) surface air temperature. In (a) the contour interval is $0.5 \mathrm{mb}$, with negative contours dashed. The lowest pressure anomaly is -3 $\mathrm{mb}$. Wind scale is indicated in lower right. In (b) light shading indicates values between $0.8^{\circ} \mathrm{C}$ and $1{ }^{\circ} \mathrm{C}$; heavy shading indicates values greater than $1{ }^{\circ} \mathrm{C}$. Contour interval is $0.2^{\circ} \mathrm{C}$. In (c) light shading indicates values between $0.6^{\circ} \mathrm{C}$ and $0.8^{\circ} \mathrm{C}$; heavy shading indicates values greater than $0.8^{\circ} \mathrm{C}$. Contour interval is $0.2^{\circ} \mathrm{C}$. From Deser and Blackmon [1993; their Figure 7].

Delworth et al. [1993], the NAO-like response of the atmosphere seems most important to the generation of SSS anomalies (through surface freshwater water flux and Ekman transport off Newfoundland and Greenland) and their subsequent impact on density gradients and the large-scale overturning circulation (see their Figure 20). The origin of the 35-yr timescale is not simple, but factors such as the accumulation time for salinity anomalies and the response of the MOC to them are key factors.
Figure 14 illustrates the spatial structure and phase relationships between these variables, based on simultaneous regression maps onto a band-passed MOC index. The positive NAO index signature is seen in the SLP regression map (Figure 14a), associated with basin wide positive anomalous SST (Figure 14b). As mentioned earlier for its observational counterpart (Figure 13), this association is different from that found at decadal and shorter timescales [see Visbeck et al., this volume] and suggests that the SST anomalies reflect enhanced oceanic heat transport rather than local atmospheric forcing. Indeed the regression map for surface currents (Figure 14e) shows a stronger Gulf Stream and North Atlantic current, with anomalous southward Ekman currents present along $\sim 55^{\circ} \mathrm{N}$. These changes in surface currents reflect not only the persistence of prior increases in deep convection south of Greenland and prior decreases in the Greenland-Iceland-Norwegian Sea (Figure 14f), but also partly the spin-up of the subtropical gyre induced by the strengthening of surface winds. Note that the positive NAO index phase (Figure 14a) is consistent with the enhanced SST gradient found along $\sim 50^{\circ} \mathrm{N}$ (Figure 14b), although lower latitudes of the Atlantic as well as Pacific SST anomalies could also be involved [Timmerman et al., 1998]. Finally, anomalously salty surface waters between $30^{\circ}-55^{\circ} \cdot \mathrm{N}$ (Figure 14d) are consistent with enhanced evaporation in that latitude band (Figure 14c).

The power spectrum of the simulated NAO at $500 \mathrm{mb}$ displayed by Timmermann et al. [1998] shows a red spectrum from interannual to decadal timescales and a clear peak in the interdecadal band (30-35 years). The redness at interannual timescales might be indicative of a moderate to strong feedback of the SST tripole onto the model NAO (see section 3). The peak at 30-35 years might reflect the two-way interaction of the NAO with the overturning circulation, but it is only a factor of 2 enhancement of power compared to the background red spectrum. Again, it must be emphasized that not all coupled GCMs show this behavior. For instance, Robertson [2001] found no such departures from climate noise when analyzing both the ECHAM4/OPYC and the CCM3/NCOM coupled models.

\subsection{Summary}

The Atlantic Ocean responds strongly to NAO changes on a broad spectrum of timescales. The climate noise scenario sees these fluctuations in ocean circulation as a passive response to (unaltered) intrinsic atmospheric variability. The presence of strong, intrinsic background NAO variability with a weak dynamical SST feedback leads to the conclusion that NAO variability is at best modulated by the Atlantic Ocean, rather than reflecting coupled dynamics like ENSO. 
a) Regr. SLP/Overt. hPa/Sv Oa

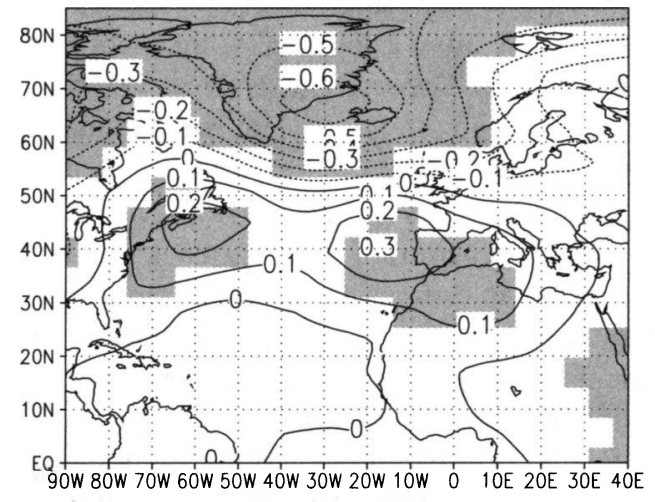

c) Regr. FWF/Overt. $\mathrm{mm} / \mathrm{d} / \mathrm{Sv} \mathrm{Oa}$

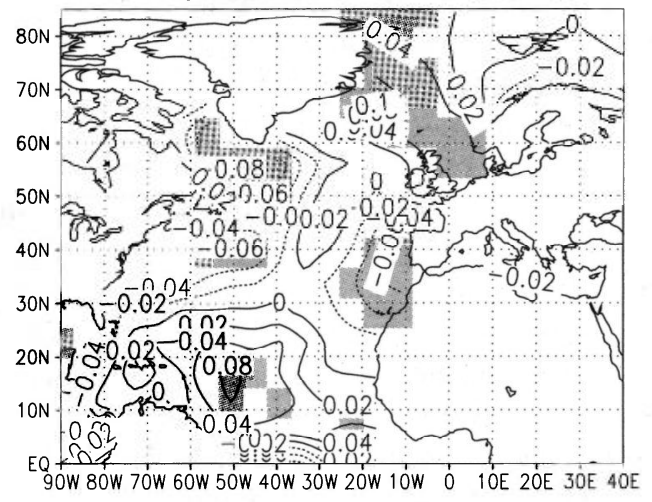

e) Regr. V25/Overt. cm/s/Sv Oa

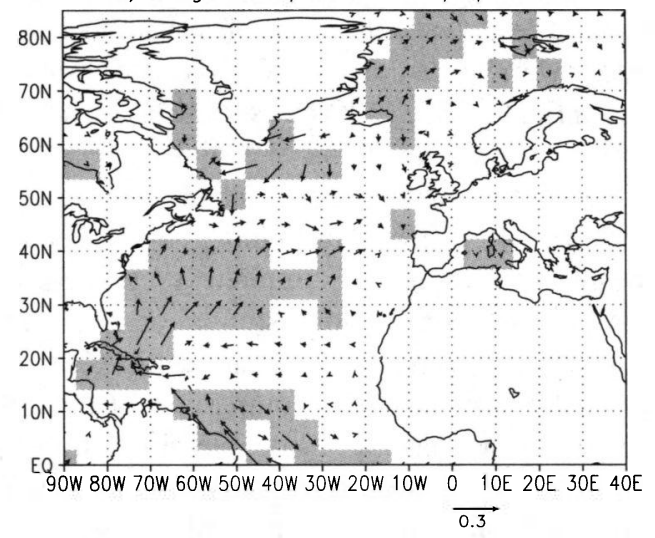

b) Regr. SST/Overt. K/Sv Oa

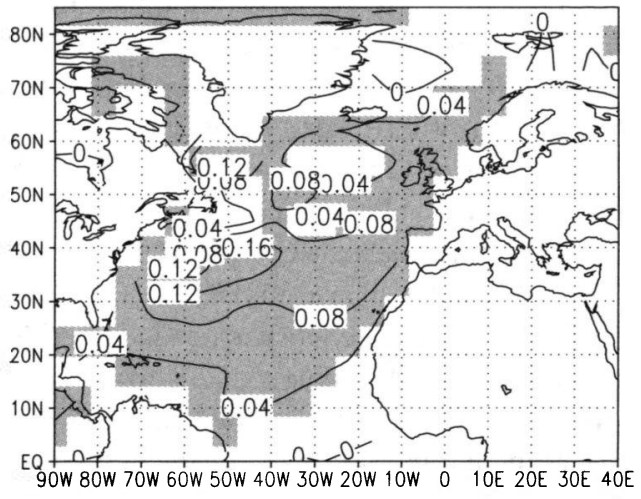

d) Regr. S25/Overt. psu/Sv Oa

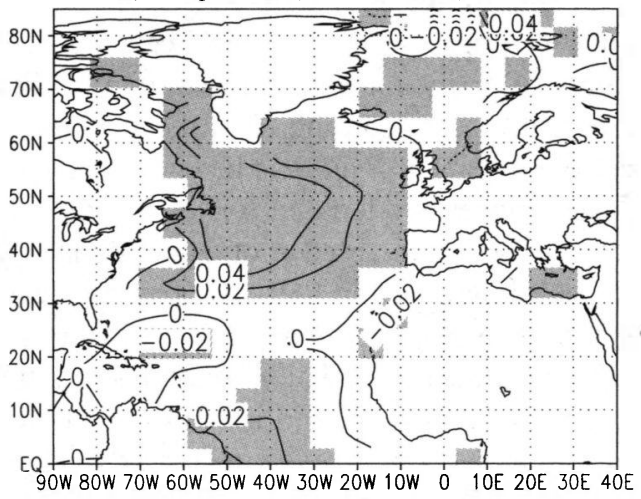

f) Regr. CON/Overt. $\mathrm{mW} / \mathrm{m}^{\wedge} 2 / \mathrm{Sv}$ Oa

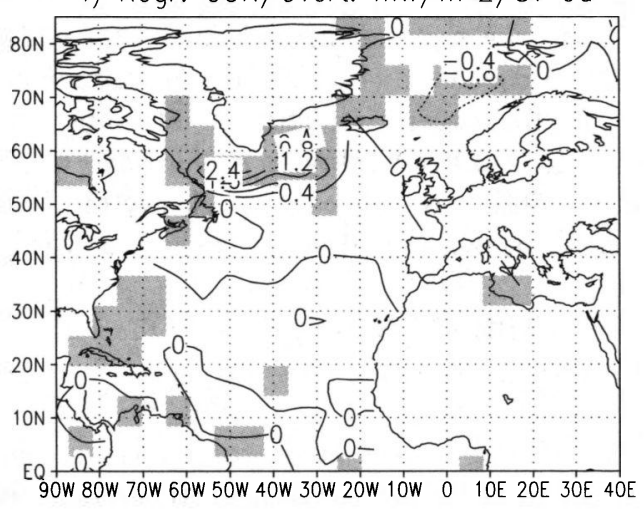

Figure 14. Simultaneous regression map of various quantities onto a band-passed (25-45 years) filtered meridional overturning index. See text for a description. From Timmermann et al. [1998; their Figure 14].

Analysis of simple models suggests that ocean heat transport variability can introduce preferred (decadal and interdecadal) timescales to which deviations from climate noise (section 2) and/or reduced thermal damping (section 3 ) are expected.

Ocean heat transport changes can arise through the advection of temperature anomalies by the mean ocean circula- tion. The corresponding advection speed combined to a length scale determined by intrinsic atmospheric processes then sets an 'advective resonance' timescale (at most a decade). Alternatively, ocean heat transport changes can arise through anomalous advection of mean temperature gradients. The associated anomalous currents can reflect the 
adjustment of the ocean to NAO surface forcing (introducing typically decadal timescales), or reflect intrinsic oceanic modes of variability (at timescales possibly longer than decadal). All these scenarios have been identified in coupled atmosphere-ocean models of various complexity, and generally result in only a modest enhancement of NAO variance at decadal to interdecadal timescales (typically a factor 2 increase). A large disparity of results exists, however, between coupled GCMs, and more work is needed to understand the origin of this spread. Possible explanations involve the different sensitivity to SST of their atmospheric component, model resolution, and perhaps differences in the mean oceanic and atmospheric states simulated. The latter may impact the models ability to simulate anomalous oceanic heat transports and their impact on the NAO.

In observations, the impact of the Atlantic Ocean on NAO variability can only be partly understood because of the limited observations of ocean currents and heat transport changes. Nevertheless, some insights can be gained from the analysis of climate indices, by looking for deviations from their expected behavior in the absence of ocean dynamics. Such departures are clearly seen in SST (and probably even more in subsurface fields if long time series were available), in SST-atmospheric surface circulation relationships that change as a function of timescale, and in the weak decadal peak suggested by the spectral analysis of long dynamical NAO indices (like those based on SLP). Recent investigation of the variability of observed net heat flux at the ocean surface also indicates a strong departure from the blue noise spectrum expected from reduced thermal damping (section 3) at interannual to decadal timescales [Czaja, submitted]. This might indicate that ocean circulation is not simply passively responding to NAO variability on decadal and longer timescales, but the observational record is clearly too short and the evidence too debatable to draw any firm conclusions.

\section{ASSESSING THE RELEVANCE OF COUPLED PROCESSES TO NAO VARIABILITY}

In this review, we have focused on the role of Atlantic airsea interactions in modulating intrinsic NAO variability. Despite various mechanisms by which the ocean could conceivably impact the atmosphere over the Atlantic sector, the modeling and observational evidence of their relevance to NAO variability appears much weaker than the zero order description based on climate noise. We now make some suggestions about what could be done in the future to better identify signatures of Atlantic air-sea interactions in observational and modeling studies of NAO variability.

It is clear from this chapter that the impact of coupled processes on NAO variability should not be evaluated sole- ly from the spectral analysis of dynamical NAO indices, like those based on sea level pressure, geopotential height or temperature. The reason is that intrinsic atmospheric processes, with a related white background spectrum, dominate the variability of these indices, generally consistent with the energy level expected from climate noise. Although the weak departure from this background spectrum displayed by the observations and simple model predictions may be of practical interest, it will never allow us to convincingly distinguish any of the proposed mechanisms from a simpler climate noise interpretation. On the other hand, there are climate variables which show much clearer signatures of oceanic forcing of NAO variability: we mentioned some results based on net surface heat flux variations (section 4), but the use of other terms of the atmospheric energy budget (like meridional energy transport) seems promising. The quality of the atmospheric reanalyses is now becoming sufficient to warrant such direct investigation of the variability in atmospheric budgets [Trenberth et al., 2002; Boer et al., 2001; Czaja, submitted], although the short length of the record is still a strong limiting factor. This is not a constraint for coupled GCMs, which could also address changes in ocean transports of freshwater and heat. These are crucial to understand how the energy and moisture budgets are closed, especially on timescales where the oceanic tendency terms become small (at least a few years).

Figure 15 sketches how 'new NAO indices' based on net surface heat flux or atmospheric energy transport can be used to gain better insight into the physical mechanisms behind NAO variability. The observations suggest a slightly red power spectrum for NAO related surface heat flux anomalies [Czaja, 2002, submitted], as schematically depicted in the upper panel (solid curve). An atmospheric model forced with climatological mean SST produces a white heat flux spectrum (middle panel), because an infinite oceanic heat capacity is implied (section 3 ). Both observations and this climate noise simulation also display an essentially white spectrum for dynamical NAO spectra like SLP (dashed curves). Thus, a comparison of the upper and middle panels suggests a reasonable simulation of NAO variability. Going, however, towards more realism (lower panel) by allowing the upper ocean to interact with the atmosphere (through coupling the AGCM to a slab ocean mixed layer) leads to a very different (blue) spectrum for surface heat flux, far from that observed (upper panel). This illustrates a caveat in the climate noise interpretation (middle panel), namely that the good simulation of the heat flux spectrum is obtained for an unphysical reason (the infinite oceanic heat capacity). The 'new NAO indices' thus appear to contain more striking signatures of the mechanisms behind NAO variability, as Figure 15 suggests the similarity of observed 
SLP (or other dynamical NAO indices) and net surface heat flux spectra is not trivial. It was suggested in section 4 that this similarity could reflect the impact of oceanic advection on NAO variability.

It also emerges from section 3.1 that one should not consider the troposphere and the upper-ocean separately. Largescale anomalies in atmospheric circulation inevitably interact with the upper ocean through exchange of heat and moisture at the sea surface and through Ekman advection. It thus seems natural to consider the troposphere and the upper ocean as a single system, possibly interacting with the geostrophic ocean circulation on interannual and longer timescales. Recent experiments by Sutton and Mathieu [submitted] emphasize this point [see also D'Andréa et al., in preparation]. By forcing an AGCM coupled to a slab ocean mixed layer with strengthened ocean heat transport convergence along the separated Gulf Stream (so-called 'Qflux' forcing), they obtained an equilibrium response of a surface low pressure and warm SST anomaly downstream of the forcing region. Within the forcing region itself, SST anomalies were unremarkable. The downstream SST anomaly thus developed both as a response to the anomalous ocean heat transport and the surface heat flux changes associated with the developing atmospheric low pressure anomalies. Solely based on the knowledge of the equilibrium SST and SLP anomaly, one would fail to interpret the response as driven by ocean changes along the separated Gulf Stream.

This tight association between the atmosphere and the upper-ocean also has implications for interpreting recent simulations of decadal NAO variability from the time-history of observed SST and sea ice anomalies [AMIP-type integrations, Venzke et al., 1999; Rodwell et al., 1999; Mehta et al., 2000; Latif et al., 2000; Hoerling et al., 2001; Robertson et al., 2001; Cassou and Terray, 2001a,b; Terray and Cassou, submitted]. If, on the one hand, we take the extreme view that changes in ocean circulation are not responsible for the generation of the observed SST tripole anomaly, the good simulation of the NAO index could merely reflect the positive feedback of the tripole on the NAO [Bretherton and Battisti, 2000]. If, on the other hand, ocean circulation changes are involved in driving the tripole SST anomalies, then the whole approach of the AMIP-type integrations is misleading [Sutton and Mathieu, submitted].

Another important need is to gain a better understanding of the differences between the two phases of NAO circulation anomalies. Unpublished observational results by Molteni and Pavan [personal communication] suggest that a negative NAO index phase is associated with reduced net diabatic heating in the atmosphere, while a positive NAO index phase corresponds to a thermally forced regime, with strong diabatic heating. The analyses of Cheng and Wallace

\section{Observations}

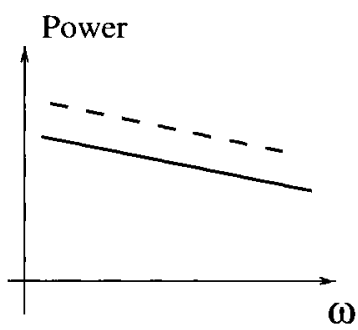

AGCM forced with SST climatology

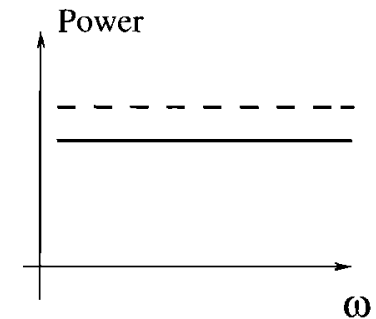

\section{AGCM coupled to a slab ocean mixed layer}

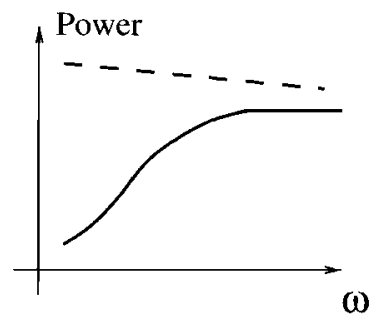

Figure 15. Schematic of observed (top panel) and simulated (middle and bottom panels) net surface heat flux (continuous line) and SLP (dashed line) power spectra as a function of frequency $\omega$.

[1993] and Peng et al. [2001] show east-west wavetrain-like structures in geopotential height associated with a positive NAO index phase, but essentially a localized meridional dipole in the negative index phase (perhaps consistent with Molteni and Pavan). Whether the interaction of the upper ocean and the atmosphere is needed or not to reproduce this asymmetry is an open issue.

Finally, some questions addressed in the context of NAO variability and air-sea interactions in this review appear as more fundamental:

- is the degree of coupling between oceanic and atmospheric fluctuations solely a consequence of the sensitivity of the atmosphere to SST changes?

- or does the degree of coupling also reflect the partition of the total (atmosphere + ocean) meridional energy transport between the ocean and the atmosphere, with strong coupling when each component plays an equal role (as in the tropics), and weak coupling when one component dominates (as in the extra tropics)?

- is the impact of cryospheric and land-vegetation anomalies on NAO variability stronger than that of the Atlantic ocean? 
It is hoped that analysis of a hierarchy of coupled oceanice-land-atmosphere models, as well as the analysis of future atmospheric and oceanic reanalysis products will give some insight into these problems.

Acknowledgments. We wish to thank four anonymous referees and the editors for their useful comments and suggestions on the original version of this chapter. A. Robertson and A. Czaja were both supported by grants from NOAA.

\section{REFERENCES}

Alexander, M. A., and C. Deser, A mechanism for the recurrence of wintertime midlatitude SST anomalies, J. Phys. Oceanogr., 25, 122-137, 1995.

Barsugli, J. J., and D. S. Battisti, The basic effects of atmosphereocean thermal coupling on midlatitude variability, J. Atmos. Sci., $55,477-493,1998$.

Battisti, D. S., U. S. Bhatt, and M. A. Alexander, A modeling study of the interannual variability of the North Atlantic Ocean, $J$. Climate, 8, 3067-3083, 1995.

Bhatt, U. S., M. A. Alexander, D. S. Battisti, D. Houghton, and L. Keller, Atmosphere-ocean interaction in the North Atlantic: near sea surface climate variability, J. Climate, 11, 1615-1632, 1998.

Bjerknes, J., The recent warming of the North Atlantic, Rossby memorial volume, in The Sea in Motion, 65-73, 1958.

Bjerknes, J., Synoptic survey of the interaction of sea and atmosphere in the North Atlantic, Geophysica Norvegia, in memory of Vilhem Bjerknes, XXIV, 3, 115-145, 1962.

Bjerknes, J., 1964. Atlantic air-sea interaction, Advances in Geophysics, 10, Academic Press, 1-82, 1964.

Bladé, I., The influence of midlatitude Ocean-Atmosphere coupling on the low - frequency variability in a GCM: Part 1. No tropical SST forcing, J. Climate, 10, 2087-2106, 1997.

Boer, G. J., S. Fourest, and B. Yu, The signature of the annular modes in the moisture budget, J. Climate, 14, 3655-3665, 2001.

Box, G. E. P., G. M. Jenkins, and G. C. Reinsel, Time Series Analysis: Forecasting and Control. 3rd ed., Prentice Hall, 1993.

Bresch, D., Coupled flow and SST patterns of the North Atlantic, Ph. D. Thesis, Swiss Federal Institute of Technology, 119 pp, 1998.

Bretherton, C. S., C. S. Smith, and J. M. Wallace, 1992. An intercomparison of methods for finding coupled patterns in climate data, J. Climate, 5, 541-560, 1992.

Bretherton, C. S., and D. S. Battisti, An interpretation of the results from atmospheric general circulation models forced by the time history of the observed sea surface temperature distribution, Geophys. Res. Lett., 27, 767-770, 2000.

Cassou, C., and L. Terray, Oceanic forcing of the wintertime low frequency atmospheric variability in the North Atlantic European sector: a study with the ARPEGE model, J. Climate, 14, 4266-4291, $2001 \mathrm{a}$.

Cassou, C., and L. Terray, Dual influence of Atlantic and Pacific SST anomalies on the North Atlantic/Europe winter climate, Geophys. Res. Lett., 28, 3195-3198, 2001b.
Cayan, D., Latent and sensible heat flux anomalies over the Northern oceans: driving the sea surface temperature, J. Phys. Oceanogr., 22, 859-881, 1992.

Cessi, P., Thermal feedback on wind stress as a contributing cause of climate variability, J. Climate, 13, 232-244, 2000.

Cessi, P., and F. Primeau, Dissipative selection of low frequency modes in a reduced-gravity basin, J. Phys. Oceanogr, 31, 127-137, 2001.

Cessi, P., and F. Paparella, Excitation of basin modes by oceanatmosphere coupling, Geophys. Res. Lett., 28, 2437-2440, 2001.

Chang, E. K. M., The influence of Hadley circulation intensity changes on extratropical climate in an idealized model, J. Atmos. Sci., 52, 2006-2024, 1995.

Chang, P., L. Ji, and H. Li, A decadal climate variation in the tropical Atlantic Ocean from thermodynamic air-sea interactions, Nature, 385, 516-518, 1997.

Cheng, X., and J. M. Wallace, Cluster analysis of the Northern Hemisphere wintertime $500 \mathrm{hPa}$ height field: spatial patterns, $J$. Atmos. Sci., 50, 2674-2696, 1993.

Colin de Verdière, A., and T. Huck, Baroclinic instability: an oceanic wavemaker for interdecadal variability, J. Phys. Oceanogr., 29, 893-910, 1999.

Costa E. D., and A. Colin de Verdière, 2002. Extended canonical correlation analysis of North Atlantic SST and SLP, Quart. $J$. Roy. Meteor. Soc., in press, 2002.

Curry, R. G., and M. S. McCartney, Ocean gyre circulation changes associated with the North Atlantic Oscillation, J. Phys. Oceanogr., 31, 3374-3400, 2001.

Czaja A., and C. Frankignoul, Influence of the North Atlantic SST anomalies on the atmospheric circulation, Geophys. Res. Lett., 26, 2969-2972, 1999.

Czaja A., and J. Marshall, On the interpretation of AGCMs response to prescribed time-varying SST anomalies, Geophys. Res. Lett., 27, 1927-1930, 2000.

Czaja A., and J. Marshall, Observations of atmosphere-ocean coupling in the North Atlantic, Quart. J. Roy. Meteor. Soc., 127, 1893-1916, 2001.

Czaja A., and C. Frankignoul, Observed impact of North Atlantic SST anomalies on the North Atlantic Oscillation, J. Climate, 15, 606-623, 2002.

Davis, R., Predictability of sea surface temperature and sea level pressure anomalies over the North Pacific Ocean, $J$. Phys. Oceanogr., 8, 249-266, 1976.

Delworth, T., North Atlantic interannual variability in a coupled ocean - atmosphere model, J. Climate, 9, 2356-2375, 1996.

Delworth, T., S. Manabe, and R. J. Stouffer, Interdecadal variations in the thermohaline circulation in a coupled ocean - atmosphere model, J. Climate, 6, 1993-2010, 1993.

Delworth, T., and M. E. Mann, Observed and simulated multidecadal variability in the North Atlantic, Clim. Dyn., 16, 661-676, 2000.

Delworth, T. L., and R. J. Greatbatch, Multidecadal thermohaline circulation variability driven by atmospheric surface flux forcing, J. Climate, 13, 1481-1495, 2000.

Deser, C, and M. L. Blackmon, Surface climate variations over the North Atlantic during winter: 1900-1989, J. Climate, 10, 393-408, 1993. 
Deser, C, and M. S. Timlin, Atmosphere-ocean interaction on weekly timescales in the North Atlantic and Pacific, J. Climate, 10, 393-408, 1997.

Dewar, W. K., On ocean dynamics in mid-latitude climate, $J$. Climate, 14, 4380-4397, 2001.

Dong, B. W., and R. T. Sutton, The dominant mechanisms of variability in Atlantic ocean heat transport in a coupled ocean-atmosphere GCM, Geophys. Res. Lett., 28, 2445-2448, 2001.

Döös, B. R., The influence of exchange of sensible heat with the Earth's surface on the planetary flow, Tellus, 2, 133-147, 1962.

Drévillon, M., L. Terray, P. Rogel, and C. Cassou, Mid-latitude Atlantic SST influence on european winter climate variability in the NCEP reanalysis, Clim. Dyn., 18, 331-344, 2001.

Drijfhout, S. S., A. Kattenberg, R. J. Haarsmaa, and F. M. Selten, The role of the ocean in midlatitude, interannual to decadal timescale climate variability in a coupled model, J. Climate, 14, 3617-3630, 2001.

Eden C., and T. Jung, North Atlantic interdecadal variability: oceanic response to the North Atlantic Oscillation (1865-1997), J. Climate, 14, 676-691, 2001.

Eden C., and J. Willebrandt, Mechanisms of interannual to decadal variability in the North Atlantic circulation, J. Climate, 14, 2266-2280, 2001.

Ferreira, D., C. Frankignoul, and J. Marshall, Coupled oceanatmosphere dynamics in a simple midlatitude climate model, $J$. Climate, 14, 3704-3723, 2001.

Feldstein, S. B., The timescale, power spectra, and climate noise properties of teleconnection patterns, J. Climate, 13, 4430-4440, 2000.

Frankignoul, C., Sea surface temperature anomalies, planetary waves and air-sea feedbacks in the middle latitude, Rev. of Geophys., 23, 357-390, 1985.

Frankignoul, C., and K. Hasselmann, Stochastic climate models, part II: application to sea-surface temperature variability and thermocline variability, Tellus, 29, 289-305, 1977.

Frankignoul, C., A. Czaja, and B. L'Hévéder, Air-sea feedback in the North Atlantic and surface boundary conditions for ocean models, J. Climate, 11, 2310-2324, 1998.

Frankignoul, C., E. Kestenare, N. Sennéchael, G. de Coëtlogon, and F. D'Andréa, On decadal-scale ocean - atmosphere interactions in the extended ECHAM1/LSG climate simulation, Clim. Dyn., 16, 333-354, 2001a.

Frankignoul, C., G. de Coëtlogon, T. M. Joyce, and S. Dong, Gulf stream variability and ocean-atmosphere interactions, J. Phys. Oceanogr., 31, 3516-3529, $2001 \mathrm{~b}$.

Gill, A. E., Atmosphere-Ocean Dynamics, Academic Press, 662 pp., 1982.

Goodman J., and J. Marshall, A model of decadal middle-latitude atmosphere-ocean coupled modes, J. Climate, 12, 621-641, 1999.

Goodman J., Interannual middle-latitude atmosphere-ocean interactions, Ph.D., Massachusetts Institute of Technology, 151 pp., 2001.

Griffies, S. M., and E. Tziperman, A linear thermohaline oscillator driven by stochastic atmospheric forcing, J. Climate, 8 , 2440-2453, 1995.
Grötzner, A., M. Latif, and T. P. Barnett, A decadal climate cycle in the North Atlantic Ocean as simulated by the ECHO coupled GCM, J. Climate, H, 831-847, 1998.

Häkkinen S., Variability of the simulated meridional heat transport in the North Atlantic for the period 1951-1993, J. Geophys. Res., 104, 10991-11007, 1999.

Halliwell, G., Simulation of North Atlantic decadal/multidecadal winter SST anomalies driven by basin-scale atmospheric circulation anomalies, J. Phys. Oceanogr., 28, 5-21, 1998.

Halliwell, G. R., and D. A. Mayer, Frequency response properties of forced climatic SSS anomaly variability in the North Atlantic, J. Climate, 9, 3575-3585, 1996.

Held, I. M., S. W. Lyons, and S. Nigam, Transients and the extratropical response to El Niño, J. Atmos. Sci., 46, 163-174, 1989.

Hendon, H. H., and D. L. Hartmann, Stationary waves on a sphere: sensitivity to thermal forcing, J. Atmos. Sci., 39, 1906-1920, 1982.

Hoerling, M. P., and M. Ting, Organization of extratropical transients during El Niño, J. Climate, 7, 745-766, 1994.

Hoerling, M. P., J. W. Hurrell, and T. Xu, Tropical origins for recent North Atlantic climate change, Science, 292, 90-92, 2001.

Hoskins, B. J., Modelling of the transient eddies and their feedback on the mean flow, in Large Scale Dynamical Processes in the Atmosphere, R. P. Pearce and B. J. Hoskins, Eds., 160-199, 1983.

Hoskins, B. J., and D. J. Karoly, The steady linear response of a spherical atmosphere to thermal and orographic forcing, $J$. Atmos. Sci., 36, 1179-1196, 1981.

Hoskins, B. J., and P. D. Sardeshmukh, A diagnostic study of the dynamics of the northern hemisphere winter of 1985-1986, Quart. J. Roy. Meteor. Soc., 113, 759-778, 1987.

Hoskins, B. J., and P. J. Valdes, On the existence of storm-tracks, J. Atmos. Sci., 47, 1854-1864, 1990.

Hou, A. Y., The influence of tropical heating displacement on the extratropical climate, J. Atmos. Sci., 50, 3553-3570, 1993.

Hou, A. Y., Hadley circulation as a modulator of the extratropical climate, J. Atmos. Sci., 55, 2437-245, 1998.

Hou, A. Y., and A. Molod, Modulation of dynamic heating in the winter extratropics associated with the cross-equatorial Hadley circulation, J. Atmos. Sci., 52, 2609-2626, 1995.

Huck, T., G. K. Vallis, and A. Colin de Verdière, On the robustness of the interdecadal modes of the thermohaline circulation, $J$. Climate, 14, 940-963, 2001.

Huck, T., and G. K. Vallis, Linear stability analysis of the threedimensional thermally-driven ocean circulation: application to interdecadal oscillations, Tellus, 53A, 526-545, 2001.

Hurrell, J. W., Decadal trends in the North Atlantic Oscillation: regional temperatures and precipitation, Science, 269, 676-679, 1995.

Hurrell, J. W., G. Ottersen, Y. Kushnir, and M. Visbeck, An overview of the North Atlantic Oscillation, this volume.

Jiang, S., F.-F., Jin, and M. Ghil, Multiple equilibria, periodic and aperiodic solutions in wind-driven, double gyre, shallow-water model, J. Phys. Oceanogr., 25, 764-786, 1995.

Jin F., A theory of interdecadal climate variability of the North Pacific Ocean-atmosphere system, J. Climate, 10, 1821-1835, 1997. 
Johnson, H. L., and D. P. Marshall, A theory for the surface Atlantic response to thermohaline variability, J. Phys. Oceanogr., 32, 1121-1132, 2002.

Joyce, T. M., C. Deser, and M. A. Spall, The relation between decadal variability of subtropical mode water and the North Atlantic Oscillation, J. Climate, 13, 2550-2569, 2000.

Kalnay E. et al., The NCEP/NCAR 40-year reanalysis project, Bull. Am. Meteorol. Soc., 103, 18567-18589, 1996.

Kaplan A., Y. Kushnir, M. Cane, and B. Blumenthal, Reduced space optimal analysis for historical datasets: 136 years of Atlantic sea surface temperatures, J. Geophys. Res., 102, 27835-27860, 1997.

Kaplan A., Y. Kushnir, and M. Cane, Reduced space optimal interpolation of historical marine sea level pressure: $1854-1992, J$. Climate, 13, 2987-3002, 2000.

Kawase, M., Establishment of deep ocean circulation driven by deep-water production, J. Phys. Oceanogr, 17, 2294-2317, 1987.

Kerr, R. A., A North Atlantic climate pacemaker for the centuries, Science, 288, 1984-1986, 2000.

Krahman, G., Visbeck, M., and G. Reverdin, Formation and propagation of temperature anomalies along the North Atlantic current, J. Phys. Oceanogr., 31, 1287-1303, 2001.

Kravtsov, S., and A. W. Robertson, Midlatitude ocean-atmosphere interaction in an idealized coupled model, Clim. Dyn., in press, 2002.

Kushnir Y., Interdecadal variations in North Atlantic sea surface temperature and associated atmospheric conditions, J. Climate, 7, 141-157, 1994.

Kushnir, Y, and I. Held, Equilibrium atmospheric responses to North Atlantic SST anomalies, J. Climate, 9, 1208-1220, 1996.

Kushnir, Y., W. A. Robinson, I. Bladé, N. M. J. Hall, S. Peng, and R. T. Sutton, Atmospheric GCM response to extratropical SST anomalies: Synthesis and evaluation, J. Climate, 15, 2233-2256, 2002.

Latif, M., and T. P. Barnett, Causes of decadal climate variability in the North Pacific/North Atlantic sector, Science, 266, 634-637, 1994.

Latif, M., and T. P. Barnett, Decadal climate variability over the North Pacific and North America: dynamics and predictability, J. Climate, 9, 2407-2423, 1996.

Latif, M., Dynamics of interdecadal variability in coupled oceanatmosphere models, J. Climate, 11, 602-624, 1998.

Latif, M., K. Arpe, and E. Roeckner, Oceanic control of decadal North Atlantic sea level pressure variability in winter, Geophys. Res. Lett., 27, 727-730, 2000.

Leith, C. E., The standard error of time - average estimates of climatic means, J. Appl. Meteor, 12, 1066-1069, 1973.

Levitus, S., Interpentadal variability of salinity in the upper $150 \mathrm{~m}$ of the North Atlantic Ocean, 1970-1974 versus 1955-1959, J. Geophys. Res., 94, 9679-9685, 1989.

Madden, R. A., A quantitative approach to long-range prediction, J. Geophys. Res., 86, 9817-9825, 1981.

Manabe, S., and R. Stouffer, Low frequency variability of surface air temperature in a 1000-year integration of a coupled ocean-atmosphere-land model, J. Climate, 9, 376-393, 1996.
Mann, M. E., R. S. Bradley, and M. K. Hughes, Global-scale temperature patterns and climate forcing over the past six centuries, Nature, 392, 779-787, 1998.

Marotzke, J., and B. Klinger, The dynamics of equatorially asymmetric thermohaline circulations $J$. Phys. Oceanogr., 30, 955-970, 2000.

Marshall, J., and D. K. So, Thermal equilibration of planetary waves, J. Atmos. Sci., 47, 963-978, 1990.

Marshall, J., H. Johnson, and J. Goodman, A study of the interaction of the North Atlantic Oscillation with the ocean circulation, J. Climate, 14, 1399-1421, 2001a.

Marshall, J., Y. Kushnir, D. Battisti, P. Chang, A. Czaja, J. Hurrell, M. Mc Cartney, Saravanan, and M. Visbeck, Atlantic climate variability, Int. J. Climatol., 21, 1863-1898, 2001b.

Meacham, S. P., Low-frequency variability in the wind-driven circulation, J. Phys. Oceanogr., 30, 269-293, 2000.

Mehta, V., M. Suarez, J. V. Manganello, and T. D Delworth, Oceanic influence on the North Atlantic Oscillation and associated Northern Hemisphere climate variations: 1959-1993, Geophys. Res. Lett., 27, 121-124, 2000.

Molteni, F., Atmospheric low-frequency variability and the role of diabatic processes, Proceedings of the international school of Physics Enrico Fermi, The use of EOS for studies of Atmospheric physics, Gille and Visconti, Eds., 1992.

Moron, V., and R. Vautard, and M. Ghil, Trends, interdecadal and interannual oscillations in global sea surface temperatures, Clim. Dyn., 14, 545-569, 1998.

Münnich, M., M. Latif, S. Venzke, and E. Maier-Reimer, Decadal oscillations in a simple coupled model, J. Climate, 11 , 3309-3319, 1998.

Neelin, J. D., and W. Weng, Analytical prototypes for oceanatmosphere interaction in midlatitudes. Part I: coupled feedbacks as a sea surface temperature dependent stochastic process, J. Climate, 12, 697-721, 1999.

Nilsson, J., Spatial reorganization of SST anomalies by stationary atmospheric waves, Dyn. of Atmos. Oce., 34, 1-21, 2001.

Nobre, P., and J. Shukla, Variations of sea surface temperature, wind stress, and rainfall over the tropical Atlantic and South America, J. Climate, 9, 2464-2479, 1996.

Nogues-Paegle, J., A. W. Robertson, C. R. Mechoso, Relationship between the North Atlantic Oscillation and river flow regimes of South America. Proceedings of the 25th Annual Climate Diagnostics and Prediction Workshop, Palisades, New York, 323-326, 2000.

Okumura, Y., S-P. Xie, A. Numaguti, and Y. Tanimoto, Tropical Atlantic air-sea interaction and its influence on the NAO, Geophys. Res. Lett., 28, 1507-1510, 2001.

Palmer, T. N., and Z. Sun, A modeling and observational study of the relationship between sea surface temperature in the north west Atlantic and the atmospheric general circulation, Quart. $J$. Roy. Meteor. Soc., 111, 947-975, 1985.

Peña, M., E. Kalnay, and M. Cai, The life span of intraseasonal atmospheric anomalies: dependence on the phase relationship with the ocean, WMO/CAS working group on numerical experiments: Progress in atmospheric and oceanic modelling. WMO, Geneva, 2001. 
Peng, S., and J. S. Whitaker, Mechanisms determining the atmospheric response to midlatitude SST anomalies, J. Climate, 12, 1393-1408, 1999.

Peng, S., W. A. Robinson, and S. Li, 2002. North Atlantic SST forcing of the NAO and relationships with intrinsic hemispheric variability, Geophys. Res. Lett., in press, 2002.

Percival, D. B., and A. T. Walden, Spectral analysis for physical applications: multitaper and conventional univariate techniques, 583 pp., Cambridge University Press, 1993.

Primeau, F., and P. Cessi, Coupling between wind driven currents and midlatitude storm tracks, J. Climate, 14, 1243-1261, 2001.

Rajagolapan, B., Y. Kushnir, and Y. Tourre, Observed decadal midlatitude and tropical Atlantic climate variability, Geophys. Res. Lett., 25, 3967-3970, 1998.

Robertson, A. W., and C. R. Mechoso, Interannual and decadal cycles in river flows of southeastern South America, J. Climate, 11, 2570-2581, 1998.

Robertson, A. W., C. R. Mechoso, and Y. J. Kim, The influence of Atlantic sea surface temperature anomalies on the North Atlantic Oscillation, J. Climate, 13, 122-138, 2000.

Robertson, A. W., On the influence of ocean-atmosphere interaction on the Arctic Oscillation in two general circulation models, J. Climate, 14, 3240-3254, 2001.

Robinson, W. A, Review of WETS-The workshop on extra-tropical SST anomalies. Bull. Am. Meteorol. Soc., 81, 567-577, 2000.

Rodwell, M. J., D. P. Rowell, and C. K. Folland, Oceanic forcing of the wintertime North Atlantic Oscillation and European climate, Nature, 398, 320-323, 1999.

Saravanan, R., Atmospheric low-frequency variability and its relationship to midlatitude SST variability: studies using the NCAR climate system model, J. Climate, 11, 1386-1404, 1998.

Saravanan, R., and J. C. McWilliams, Advective ocean-atmosphere interaction: an analytical stochastic model with implications for decadal variability, J. Climate, 11, 165-188, 1998.

Saravanan, R., G. Danabasoglu, S. C. Doney, and J. C. Mc Williams, Decadal variability and predictability in the midlatitude ocean-atmosphere system, J. Climate, 13, 1073-1097, 2000.

Sardeshmukh, P. D., and B. J. Hoskins, The generation of global rotational flow by steady idealized tropical divergence, J. Atmos. Sci., 45, 1228-1251, 1988.

Selten, S. M., R. J. Haarsma, and J. D. Opsteegh, On the mechanism of North Atlantic decadal variability, J. Climate, 12, 1956-1973, 1999.

Shutts, G. J., Some comments on the concept of thermal forcing, Quart. J. Roy. Meteor. Soc., 113, 1387-1394, 1987.

Stephenson, N. C., V. Pavan, and R. Bojariu, Is the North Atlantic Oscillation a random walk? Intl. J. Climatol, 20, 1-18, 2000.

Sutton R. T., and M. R. Allen, Decadal predictability of North Atlantic sea surface temperature and climate, Nature, 388 , 563-567, 1997.

Sutton, R. T., W. A. Norton, and S. P. Jewson, The North Atlantic Oscillation - What role for the Ocean? Atm. Sci. Lett., (doi:10.1006/asle.2000.0018), 2001.

Sweet, W., R. Fett, J. Kerling, and P. La Violette, Air-sea interaction effects in the lower troposphere across the North wall of the Gulf Stream, Mon. Weather Rev., 109, 1042-1052. 1981.
Taylor, A. H., and J. A. Stephens, The North Atlantic Oscillation and the latitude of the Gulf Stream, Tellus, 50A, 134-142, 1998.

te Raa, L. A., and H. A. Dijkstra, Instability of the thermohaline ocean circulation on interdecadal time scales, J. Phys. Oceanogr. 32, 138-160, 2002.

Thompson, D. W. J., and J. M. Wallace, Annular modes in the extratropical circulation. Part I: month-to-month variability, $J$. Climate, 13, 1000-1016, 2000.

Thompson, D., S. Lee, and M. P. Baldwin, Atmospheric processes governing the North Atlantic Oscillation/Northern hemisphere annular mode, this volume.

Timmerman, A., M. Latif, R. Voss, and A. Grötzner, Northern hemispheric interdecadal variability: a coupled air-sea mode, $J$. Climate, 11, 1906-1931, 1998.

Ting, M., The stationary wave response to a midlatitude SST anomaly in an idealized GCM, J. Atmos. Sci., 48, 1249-1275, 1991.

Ting, M., and S. Peng, Dynamics of early and middle winter atmospheric responses to the Northwest Atlantic SST anomalies, J. Climate, 8, 2239-2254, 1995.

Tourre Y. M., Rajagolapan B. and Y. Kushnir, Dominant patterns of climate variability in the Atlantic Ocean during the last 136 years, J. Climate, 12, 2285-2299, 1999.

Trenberth K. E., D. Stepaniak, and J. M. Caron, Interannual variations in the atmospheric heat budget, J. Geophys. Res., 10.1029/2000JD000297, 2002.

Venzke, S., M. R. Allen, R. T. Sutton, and D. P. Rowell, The atmospheric response over the North Atlantic to decadal changes in sea surface temperatures, J. Climate, 12, 2562-2584, 1999.

Visbeck, M., H. Cullen, G. Krahman, and N. Naik, An ocean model's response to North Atlantic Oscillation - like wind forcing, Geophys. Res. Lett., 25, 4521-4524, 1998.

Visbeck, M., R. Curry, B. Dickson, E. Chassignet, T. Delworth, and G. Krahman, The ocean's response to North Atlantic Oscillation variability, this volume, 2002.

von Storch, H., and F. W. Zwiers, Statistical Analysis in Climate Research, Cambridge University Press, 499 pp. 1999.

Wajsowicz, R.C., Adjustment of the ocean under buoyancy forces, II: the role of planetary waves, J. Phys. Oceanogr, 16, 2115-2136, 1986.

Wallace, J. M., C. Smith, and Q. Jiang, 1990. Spatial patterns of Atmosphere-Ocean interaction in the Northern hemisphere, $J$. Climate, 3, 990-998, 1990.

Watanabe, M., and M. Kimoto, Tropical-extratropical connection in the Atlantic atmosphere-ocean variability, Geophys. Res. Lett., 26, 2247-2250, 1999.

Watanabe, M., and M. Kimoto, On the persistence of decadal SST anomalies in the North Atlantic, J. Climate, 13, 3017-3028, 2000a.

Watanabe, M., and M. Kimoto, Ocean Atmosphere thermal coupling in the North Atlantic: a positive feedback, Quart. J. Roy. Meteor. Soc., 126, 3343-3369, 2000b.

Woodruff, S. D., R. J. Slutz, R. L. Jenne, and P. M. Steurer, A comprehensive ocean-atmosphere data set, Bull. Am. Meteorol. Soc., $68,1239-1250,1987$. 
Wunsch C., The interpretation of short climate records, with comments on the North Atlantic Oscillation and Southern Oscillations, Bull. Am, Meteorol. Soc., 80, 245-255, 1999.

Xie, S-P., and Y. Tanimoto, A pan-Atlantic decadal oscillation, Geophys. Res. Lett., 25, 2185-2188, 1998.

Yang, J., A linkage between decadal climate variations in the Labrador sea and the tropical Atlantic ocean, Geophys. Res. Lett., 26, 1023-1026, 1999.

Zorita, E., and C. Frankignoul, Modes of North Atlantic decadal variability in the ECHAM1/LSG coupled atmosphere-ocean general circulation model, J. Climate, 10, 183-200, 1997.
A. Czaja, Department of Earth, Atmospheric and Planetary Sciences, Massachusetts Institute of Technology, 77 Massachusetts Ave,, Cambridge, MA, 02139-4397, USA. czaja@ocean.mit.edu

A. W. Robertson, International Research Institute for Climate Prediction, P.O. Box 1000, Palisades, NY, 10964-8000, USA. awr@iri.columbia.edu

T. Huck, Laboratoire de Physique des Océans, Université de Bretagne Occidentale, 29285 Brest, France.

thuck@univ-brest.fr 